\title{
The Welfare Costs of Tiebout Sorting with True Public
}

\author{
Goods*
}

\author{
Florian Kuhlmey ${ }^{\dagger}$ and Beat Hintermann ${ }^{\dagger \ddagger}$
}

March 28, 2019

\begin{abstract}
We develop a model of Tiebout sorting based on decentralized income taxation, which allows for spillovers and imperfect rivalry in consumption of the publicly provided good. We identify three sources of welfare loss from decentralization: Imperfect redistribution, inter-jurisdictional free-riding, and inefficient residential choice. Whereas the welfare loss from imperfect redistribution decreases and that from free-riding rises unambiguously as the publicly provided good becomes more pure, the welfare loss from the inefficient residential choice depends non-monotonically on spillovers and rivalry. The equilibrium can be characterized by relative crowding of either the rich or the poor municipality. Our results imply that the characteristics of the publicly provided good are an important determinant for the welfare costs of decentralization.
\end{abstract}

JEL Codes H21, H23, H41, H77; Q58; R13, R23, R50.

Keywords Public goods; Tiebout; local income taxation; fiscal federalism; decentralization; free-riding.

${ }^{*}$ We are grateful for valuable comments by the Editor-in-Chief Ron Davies and two anonymous referees. We also thank Kurt Schmidheiny, who provided valuable inputs. Earlier versions of this work have been presented at the ZEW Public Finance Conference 2015 in Mannheim, the EAERE conference 2015 in Helsinki, the IIPF conference 2015 in Dublin, the SSES conference 2018 in St. Gall and at MCC Berlin. We thank the discussants and the participants for useful comments and suggestions. Any remaining errors are our own.

$\dagger$ University of Basel, Faculty of Business and Economics, Peter-Merian-Weg 6, CH-4002 Basel, Switzerland.

${ }^{\ddagger}$ CESifo. Corresponding author: b.hintermann@unibas.ch. 


\section{Introduction}

In the broader literature of public finance, there is a long-standing debate about the relative merits of a centralized and a decentralized public provision of goods. This debate is complicated by two features: Households and firms are typically mobile, and there may be spillovers of the publicly provided good across jurisdictions. Examples include environmental quality, infrastructure (e.g., airports) and recreational facilities (e.g., sports stadiums or public parks) 1

With mobile households and firms, sub-national jurisdictions compete for the tax base by offering a package of tax rates and public goods. This issue is the subject of (capital) tax competition model ${ }^{2}$ and of multi-jurisdiction models in the spirit of Tiebout (1956) that focus on the endogenous sorting of households into regions. $3^{3}$ In these models, the public good is almost always modeled as a publicly provided private good in the sense that it is rival in consumption and can only be used by people living in the jurisdiction where it is produced. An exception is a series of papers referred to as "environmental federalism" by Oates (1999), which allow for household mobility and explicitly focus on inter-regional spillovers, but which abstract from fiscal externalities by assuming head taxes rather than the kind of non-benefit taxation (e.g., on capital, property or income) that is the primary source of revenue for regional and local governments worldwide.

In this paper, we combine the insights from these two sub-strands of the literature and propose a model of household sorting into municipalities that use income taxes to finance a true public good $4^{4}$ To do this, we extend Schmidheiny's (2006b) framework by allowing for various degrees of spillovers and rivalry of the publicly provided good. Using our model, we carry out a normative analysis in the spirit of Calabrese et al. (2012) to assess the gross costs of decentralization. Throughout the paper, we abstract from the benefits of decentralization

\footnotetext{
${ }^{1}$ According to Oates' (1972) decentralization theorem, every publicly provided good or service should be provided by the lowest possible entity which contains all households affected by the public intervention (subsidiarity principle). Since this requires an impracticable plurality of entities, this perfect correspondence does usually not apply in practice. Kaplow (2006) offers an alternative view on what kind of public goods should be provided at what level of government, depending on the distributive incidence of such provision.

${ }^{2}$ In capital tax competition models, the population is usually assumed to be fixed. For reviews of this literature, see Wilson (1999) and Wilson \& Wildasin (2004).

${ }^{3}$ Reviews of sorting models are provided by Ross \& Yinger (1999), Epple \& Nechyba (2004), Boadway \& Tremblay (2012) and Bruelhart et al. (2015).

${ }^{4}$ Although the majority of multi-jurisdiction models focus on property taxation, income taxes represent the most important source of revenue for municipalities worldwide (Bruelhart et al. 2015, p. 1138). Income taxes are used in several thousand municipalities in the USA (Henchman \& Sapia 2011). For an analysis about income tax competition in Switzerland, see Feld \& Kirchgaessner (2001).
} 
due to mitigating information asymmetries and rent-seeking (as in Sato 2003), and from an endogenous formation of jurisdictions, which is the focus in Gravel \& Thoron (2007), Gravel \& Oddou (2014) and Oddou (2016) $!^{5}$

In the theory section, we derive the equilibrium conditions of the model and characterize the fiscal externality that results from the decentralized locational choice (defined as the "jurisdictional choice externality", or JCE, by Calabrese et al. 2012). We further derive a modified Samuelson condition that depends on the degree of spillovers and rivalry in consumption of the publicly provided good, and to which we can compare the decentralized outcome. In the decentralized equilibrium, municipalities differ according to their income tax rate, the level of public consumption, and housing prices, all of which are endogenous. Because the model is too complex to solve analytically, we implement it numerically. We restrict our analysis to equilibria that are characterized by segregation along (fixed) income, such that the richest member of a municipality is poorer than the poorest member of the next-richer municipality. Our results imply that spillovers and congestion are important determinants of the welfare loss from decentralization, and that the special case of a publicly provided private good, on which the literature previously focused, only allows for a limited understanding of the implications of tax-induced household sorting.

We decompose the welfare loss associated with moving from a unified social planner model to the fully decentralized equilibrium with majority voting into the following sources: (1) imperfect redistribution, (2) inter-municipal free-riding and (3) the jurisdictional choice externality (JCE). All three inefficiencies depend on the characteristics of the public good. Whereas the welfare loss from imperfect redistribution decreases in the level of spillovers (because public consumption becomes more similar across regions and therefore less redistribution is required), the welfare loss from free-riding increases with spillovers, which is intuitive.

The effect of spillovers on (3) is non-monotonic. As spillovers increase, the welfare loss from the JCE first decreases, then increases, and finally decreases again. The intuition is as follows: At low level of spillovers, the rich region is relatively crowded, such that we observe the "poor chase rich" effect identified in the previous literature that focuses on publicly provided

\footnotetext{
${ }^{5}$ Whereas Oddou (2016) allows for spillovers and abstracts from a housing market, Gravel \& Oddou (2014) include a housing market but abstract from spillovers. In this paper, we abstain from investigating the necessary and sufficient conditions in a model that includes both a housing market and spillovers, and instead focus on the inefficiencies inherent in such a setup.
} 
private goods (see, e.g., Bucovetsky \& Glazer 2014). Poorer households buy (small amounts of) housing in the rich community in order to benefit from high public consumption at relatively low personal tax payments. As spillovers increase from zero to positive levels, the incentive of the poor to crowd into the rich region decreases and eventually disappears, and along with it the welfare loss due to (3).

As spillovers increase further, the inefficiency of the household distribution moves in the other direction: For intermediate levels of spillovers, we observe that it is in fact the poor municipality that is crowded, relative to the population distribution that a social planner would choose. This "poor flee rich" effect is new to the literature, and it is due to the fact that households in the poor municipality can free-ride on the public production of the rich municipality while enjoying low taxe rates and housing prices. This creates an inefficiency that increases with the level of spillovers. Finally, as spillovers increase even more, public consumption, taxes and housing prices converge across the municipalities such that the JCE becomes less relevant, and the resulting welfare loss decreases.

In technical terms, our model is in the tradition of "multi-jurisdiction" sorting models, in which voters decide about the level of a public good that is financed by local nonbenefit taxes ${ }^{6}$ Unlike the original Tiebout model that focuses on heterogeneous preferences (and which was proposed as a solution to the information problem haunting public production), sorting in these models largely occurs according to income, which is inefficient. In these models, households' residential choice (suburbs) is independent of their workplace (center), such that income can be treated as fixed, which greatly facilitates the identification of an equilibrium. With two exceptions, the public good modeled is a publicly provided private good (usually interpreted as school quality) that is perfectly rival and excludable. To our knowledge, the only previous sorting models that include residence-based nonbenefit taxes and truly public goods are by Nechyba (1997) and Oddou (2016). These papers focus on the existence of equilibria and on the endogenous formation of jurisdictions, from which we abstract. We apply the necessary conditions for income sorting derived by Schmidheiny (2002) and focus on equilibria that we identify numerically. We treat the number of municipalities as given, considering the stylized

\footnotetext{
${ }^{6}$ This literature is largely shaped by Dennis Epple and co-authors and includes, e.g., Epple \& Zelenitz (1981), Epple \& Romer (1991), Epple \& Platt (1998), Epple et al. (2001), and focuses on the example of property taxes. Applications based on local income taxation include Hansen \& Kessler $(2001 a \mid b)$ and Schmidheiny $(2006 b a)$. Calabrese et al. (2012) is the only paper in this literature that focuses on the welfare implications of decentralization.
} 
fact that most jurisdictional borders are have a long history of existence and will not be changed due to economic outcomes alone. We describe the equilibria numerically and carry out a normative analysis of the costs of decentralization, which is not done by Nechyba (1997) and Oddou (2016). In this sense, our paper is a complement to their earlier work.

Kuhlmey (2017) builds on the current framework and allows for the presence of an upperlevel government that imposes a fiscal equalization scheme and a progressive income tax function, upon which municipalities choose linear multipliers. Fiscal equalization between municipalities turns out to be an effective measure to counter-balance the incentives for segregation induced by progressive taxes (which are stronger than when using a linear income tax). Kuhlmey abstracts from a normative analysis and does not allow for variations in the characteristics of the publicly provided good, both of which are central in the context of the current paper.

A number of papers have focused on the implications of inter-regional spillovers with mobile households using models of benefit taxation. Wellisch (1994) shows that the decentralized provision of public goods with interjurisdictional spillovers is efficient, provided that migration is costless, and is efficient for the richer region even if migration costs are important. The underlying intuition is that with costless migration, utility levels are equalized across regions, and no region can make itself better off at the expense of others. Free-riding would simply induce more immigration, driving returns to labor down until utilities are equalized once again (this is modeled by assuming decreasing returns to labor in each region, following the work by Myers 1990, Mansoorian \& Myers 1993). If migration is costly, regional welfare will not be equalized, but the rich region has an incentive to provide transfer payments to other regions in order to limit immigration. Positive spillovers replace these transfer payments one for one, such that as a result, the rich region has an incentive to produce the socially optimal amount of the public good 7 Hoel \& Shapiro (2003, 2004) and Hoel (2004) generalize Wellisch's 1994 model to different policy instruments available to the regional governments and different assumptions about the mobility of the population. Bloch \& Zenginobuz $(2006)$ examine the consequence of asymmetric spillovers across regions, and Bucovetsky (2011) derives sufficient conditions for decentralized public policy to be Pareto efficient. This model class is very different from ours, because it abstracts from fiscal inefficiencies and does not endogenize the policy outcome as a

"Silva \& Caplan (1997), Caplan et al. (2000) and Caplan \& Silva (2011) extend these models by adding a federal government that can enforce interjurisdictional transfers. Because the example provided in these papers is often the environment, this literature has been referred to as "environmental federalism" by Oates (1999). 
consequence of household (and voter) mobility, but instead focuses on the strategic interaction among regions using game theoretical tools. Despite the different modeling framework, we generate qualitatively similar results in the sense that the presence of spillovers can mitigate utility differences across regions that tend to arise from decentralization.

Last, spillovers have also been investigated in the context of capital tax competition. In these models, capital flows across jurisdictional borders but the population is held fixed, which sidesteps many of the issues related to endogenous sorting and voting that are a central focus of Tiebout-inspired sorting papers like ours. Bjorvatn \& Schjelderup (2002) and Ogawa (2006) find that spillovers reduce the incentives for capital tax competition, and can even eliminate them in the special case of pure public goods.8 In Bloch \& Zenginobuz (2015), capital is fixed and labor is the (imperfectly) mobile factor that moves across borders in response to regional tax rates set by regional governments. The authors show that mobility increases the cost of decentralization, and that the regional tax rate is a non-monotonic function of inter-regional spillovers. Again, these results are qualitatively similar to ours, despite having been derived using a very different modeling framework.

In the next section, we present our theoretical model, which we implement numerically in section 3 . Section 4 contains the welfare analysis, and section 5 concludes.

\section{Model}

We start by describing the general structure of the decentralized model and provide the necessary conditions for an equilibrium characterized by the self-selection of households into jurisdictions or municipalities according to income. We will refer to municipalities for the remainder of the paper, because we have a metropolitan model in mind where the choice of the residential location is independent of the choice of the work location (usually assumed to be in the central business district); however, the model could also be applied to larger jurisdictions such as states or cantons, provided that income possibilities are independent of the location of residence. We also formulate a first-best version of the model, where a social planner determines the distri-

\footnotetext{
${ }^{8}$ For the special case of positive spillovers that are proportional to a fixed capital stock, Ogawa \& Wildasin (2009) show that local policy choices are efficient. However, if capital supply is elastic, the decrease in spillovers from other regions is smaller, making it optimal for regional governments to choose tax rates that are lower than what would be socially optimal (Eichner \& Runkel 2012). Armbruster \& Hintermann (2019) add a federal government and discuss the conditions under which the outcome is efficient.
} 
bution of households, the tax rate and thus the level of publicly provided goods in each region, and also has access to an individualized transfer scheme.

\subsection{Decentralized equilibrium}

The model consists of $j=1, \ldots, J$ municipalities. Each municipality decides upon the production of a publicly provided good $G_{j}$, which is financed using a linear income tax rate $t_{j}$. The municipality-specific tax rate is determined by majority vote of the residents (see below). We choose quantities that set the unit cost of public production to one, such that the level of public provision in municipality $j$ is given by

$$
G_{j}=t_{j} Y_{j}
$$

where $Y_{j}$ refers to aggregate income in municipality $j$. With spillovers and imperfect rivalry, consumption of the publicly provided good is determined by

$$
g_{j}=\frac{G_{j}+\sigma \sum_{i \neq j} G_{i}}{\left(N_{j}+\nu \sum_{i \neq j} N_{i}\right)^{\rho}},
$$

where $N_{j}$ is the population residing in municipality $j$ and $\sigma \in[0,1]$ determines the degree of interjurisdictional spillovers, with $\sigma=0$ implying no spillovers and $\sigma=1$ implying perfect spillovers.9 The numerator in (2) contains public provision in the home municipality $j$ and in the other municipalities $i \neq j$, weighted by the spillover parameter $\sigma$, which means that spillovers are symmetric between jurisdictions. Rivalry in consumption enters in the denominator via $\rho \in[0,1]$ : If $\rho=0$, there is no rivalry in consumption of the publicly provided good, whereas rivalry is perfect at $\rho=1$. The term $N_{j}+\nu \sum_{i \neq j} N_{i}$ is the mass of households that have access to the publicly provided good in $j$. The 'neighborhood' parameter $\nu \in[0,1]$ is a parameter that measures the degree to which households from outside municipality $j$ have access to consume the publicly provided good in $j$. While $\sigma$ measures the degree to which a public good 'spills out' of a region (e.g., in the form of water quality), $\nu$ measures the degree

\footnotetext{
${ }^{9}$ Our equations (1) and (2) representing the production and consumption levels of the publicly provided good have been inspired by Oddou (2016). The definitions of production $G_{j}$ and consumption $g_{j}$ imply that these variables have different units: While $G_{j}$ is equal to aggregate production in $j$ and therefore measured in units of the publicly provided good, consumption $g_{j}$ describes the amount that every household in $j$ can consume and is therefore measured in units of the publicly provided good per household.
} 
to which the population from other regions can 'spill in' and consume the public goods (e.g., public infrastructure) in region $j$. The extent to which this deteriorates congestion in region $j$ depends on $\rho$. In our numerical implementation, we assume that $\sigma=\nu$. However, we do not restrict our model at this stage.

The combination of $(\rho=0, \sigma=\nu=1)$ describes the case of a pure public good, where consumption equals the sum of what all municipalities provide. At the other end of the spectrum, the combination ( $\rho=1, \sigma=\nu=0$ ) describes a purely private good, of which a household living in municipality $j$ consumes the amount $g_{j}=G_{j} / N_{j}$. Any parameter combination in between these limits describes an intermediate case ${ }^{10}$ Furthermore, the model could be adapted to the case of asymmetric spillovers ${ }^{11}$

Housing is supplied elastically by absentee landlords based on a constant returns to scale (CRS) technology. Housing market clearing implies that

$$
H_{j}^{S}\left(p_{j}\right)-\int_{\underline{y_{j}}}^{\overline{y_{j}}} h^{j}(y) f(y) \mathrm{d} y=0 \quad \forall j
$$

where $H_{j}^{S}$ is the aggregate housing supply function and the integral describes the aggregate of households' demand for housing in municipality $j$. Because the amount of available land is fixed, the marginal cost of housing is increasing in housing demand. Thus, the attractiveness of the tax-expenditure package of a municipality is capitalized into housing prices $p_{j}$. No other taxes or publicly provided goods exist, such that from the perspective of households, municipalities are fully characterized by the triplet $\left(p_{j}, t_{j}, g_{j}\right){ }^{12}$ This leads to different possible tradeoffs between the attributes of the municipalities. The only thing we can say is that no municipality

\footnotetext{
${ }^{10}$ Not all parameter combinations are equally meaningful. For example, it would make no sense to define the publicly provided good as perfectly rival in consumption $(\rho=1)$, but at the same time allow for interjurisdictional spillovers $(\sigma>0)$ or neighbors to consume $(\nu>0)$, because any outsiders could be easily excluded from consuming the good at home or by crossing borders. The combination $(\rho=\sigma=0)$ would describe a club good for which households from outside the municipality can be excluded.

${ }^{11}$ Instead of specifying $\nu$ and $\sigma$ as single parameters, we would define both as $J \times J$ matrices, with $\nu_{j j}=$ $\sigma_{j j}=1.0 \leq \sigma_{i j} \leq 1 \forall i \neq j$ is then the degree of spillover from municipality $i$ to $j$, and $0 \leq \nu_{i j} \leq 1 \forall i \neq j$ describes the extent to which households from municipality $i$ have access to consume the publicly provided good in $j$. (2) would then read as $g_{j}=\sum_{i=1}^{J} \sigma_{i j} G_{i} /\left(\sum_{i=1}^{J} \nu_{i j} N_{i}\right)^{\rho}$. Since we rely on symmetric spillovers in our numerical application, we decided to keep the general model as simple as possible. Asymmetric spillovers could be used to reflect the spacial structure of a metropolitan area, whereas the assumption of symmetric spillovers renders the model essentially spaceless.

${ }^{12}$ This differs from models of property tax competition where the tax and the housing price are combined, such that municipalities differ in two dimensions only: the gross-of-tax housing price, and the level of the publicly provided good. Note that $G_{j}$ is irrelevant for households' relocation decisions, since what matters for utility is the consumption level $g_{j}$ and not municipality $j$ 's contribution to the publicly provided good.
} 
can be worse off along all three dimensions, as no one would live in this municipality (which would drive down the resulting housing price).

Households differ with respect to exogenous income $y$, which is distributed on the domain $(\underline{y}, \bar{y})$ according to the probability density function $f(y)$. Conditional on their residential choice (and thus the level of public consumption), they maximize their utility by choosing their preferred level of numeraire consumption $x^{j}$ and housing $h^{j}$, subject to a budget constraint. Solving this problem yields an indirect utility function, which depends on municipality characteristics and personal income:

$$
V\left(p_{j}, t_{j}, g_{j} ; y\right)=\max _{x, h} U\left(x^{j}, h^{j}, g_{j}\right) \quad \text { s.t. } \quad y\left(1-t_{j}\right)=x^{j}+p_{j} h^{j}
$$

Households choose the municipality in which they wish to reside. If the endogenous locational choice of households leads to an equilibrium where the richest member of any given municipality is poorer than the poorest member of the next richer municipality, this is referred to as (complete) segregation by income. For the case of local income taxation, Schmidheiny (2002) identified two sufficient conditions for income segregation, provided that an equilibrium exists: ${ }^{13}$ First, the marginal rates of substitution between any arguments of the indirect utility function must change monotonically in income, which is known as the 'single-crossing condition', because it ensures that the indifference curves of two households with different incomes cross only once. Second, preferences have to satisfy a condition called 'proportional shift in relative preferences' for income. One class of utility functions that complies with the Schmidheiny (2002) conditions is the Stone-Geary utility function, which adds subsistence levels of consumption to the Cobb-Douglas utility function. We use this in Section 3. The migration behavior of households depends on their income and their preferences, which determine how households trade off private and public consumption as well as tax rates. This trade-off does not change if we introduce varying degrees of spillovers or congestion, as they only affect the production technology of the public provision. Therefore, the necessary conditions identified for publicly provided private goods apply here as well.

We order municipalities in ascending order of average income such that under perfect income

\footnotetext{
${ }^{13}$ Note that Schmidheiny cannot establish conditions for the existence of an equilibrium, but can show that if one exists, his conditions ensure that it is characterized by a segregation of households according to income.
} 
segregation, every member in municipality $j$ is (weakly) richer than every member of municipality $j-1$. For any two adjacent municipalities $j$ and $j-1$, there exists a household with income $\widetilde{y}_{j-1, j}$ that is indifferent between them. Formally, this means that $V\left(p_{j}, t_{j}, g_{j} ; \widetilde{y}_{j-1, j}\right)=$ $V\left(p_{j-1}, t_{j-1}, g_{j-1} ; \widetilde{y}_{j-1, j}\right)$. The indifferent household is thus determined by the characteristics of both municipalities. A migration equilibrium under income segregation requires that the indifferent households are the municipality 'borders', i.e., that $\widetilde{y}_{j-1, j}=\underline{y_{j}}\left(=\overline{y_{j-1}}\right)$ and $\widetilde{y}_{j, j+1}=\overline{y_{j}}\left(=\underline{y_{j+1}}\right)$, where the lower and upper bar represents the poorest and the richest households in municipality $j$, respectively. A sorting equilibrium has been reached if nobody has an incentive to move:

$$
\forall y \in\left[\underline{y_{j}}, \overline{y_{j}}\right]: \quad V\left(p_{j}, t_{j}, g_{j} ; y\right)-V\left(p_{i}, t_{i}, g_{i} ; y\right) \geq 0 \forall i \neq j \forall j .
$$

The equation holds with equality only for the border households between municipalities that are adjacent in the income ranking ${ }^{14}$

Households vote about their preferred tax rate, which we formalize as a (non-cooperative) two-stage game ${ }^{15}$ In the first stage, households choose their location and buy housing, correctly anticipating the voting outcome in every municipality. In the second stage, households determine the level of public production along with the necessary tax rate to satisfy the budget constraint by majority vote, and consumption takes place. When voting, we therefore follow Calabrese et al. (2012, Footnote 9) and assume that households take the distribution of households, their consumption decisions, as well as the aggregate income and population in each municipality (defined by $Y_{j}=N_{j} \int_{\underline{y_{j}}}^{\overline{y_{j}}} y f(y) \mathrm{d} y$ and $N_{j}=N \int_{\underline{y_{j}}}^{\overline{y_{j}}} f(y) \mathrm{d} y$, respectively, with $N$ the total population) as given. Furthermore, they perfectly foresee the other municipalities' contributions to the publicly provided good ${ }^{16}$

\footnotetext{
${ }^{14}$ The empirically more realistic case of an 'imperfect sorting' of households requires that households differ with respect to income and additionally some preference parameter, as in Epple \& Platt (1998). The model would then require that (5) holds for all values of the second source of heterogeneity, i.e. that there is income segregation conditional on the value of the preference parameter (see Schmidheiny 2002, 2006b).

15 Loeper (2017) compares public consumption levels in a non-cooperative setup with the case of Coasian cooperation. Abstracting from household mobility and tax competition, he finds that cooperation mitigates the free-riding incentives only if the demand for the publicly provided good is not too inelastic, irrespective of the size of the spillovers.

${ }^{16}$ There is an ongoing debate in the literature concerning voter myopia. Even if voters are assumed to be 'myopic' as in Schmidheiny (2006b), because they do not consider migration responses and housing demand reactions to a marginal change in the municipalities' tax rates, this is of no consequence in an equilibrium, where nobody has an incentive to move or to change housing consumption by definition. In this sense, the difference between myopic and perfectly rational voters is moot. Outside of the equilibrium, however, the degree of voter
} 
The maximization problem for the voter with income $y$ is given by

$$
\max _{t_{j}, g_{j}} V\left(p_{j}, t_{j}, g_{j} ; y\right) \quad \text { s.t. } \quad g_{j}=\frac{t_{j} Y_{j}+\sigma \sum_{i \neq j} G_{i}}{\left(N_{j}+\nu \sum_{i \neq j} N_{i}\right)^{\rho}}
$$

The median voter $y_{j}^{m}$ in municipality $j$ is implicitly defined by $\int_{\underline{y_{j}}}^{y_{j}^{m}} f(y) \mathrm{d} y=\frac{1}{2} \int_{\underline{y_{j}}}^{\overline{y_{j}}} f(y) \mathrm{d} y$. Due to the monotonicity of preferences, the median income households are the only households that maximize utility. All others do not obtain their optimal tax rate, although they (weakly) prefer the triple $\left(p_{j}, t_{j}, g_{j}\right)$ in their municipality to that in other municipalities.

Substituting the municipality's budget constraint and considering $y=y_{j}^{m}$, the first-order condition with respect to $t_{j}$ is

$$
\frac{\partial V\left(p_{j}, t_{j}, g_{j} ; y_{j}^{m}\right)}{\partial t_{j}}+\frac{\partial V\left(p_{j}, t_{j}, g_{j} ; y_{j}^{m}\right)}{\partial g_{j}} \frac{Y_{j}}{\left(N_{j}+\nu \sum_{i \neq j} N_{i}\right)^{\rho}}=0
$$

This implicitly defines the tax rate for every municipality for given contributions to the publicly provided good of the other municipalities. A voting outcome in our local income tax competition model constitutes a Nash equilibrium such that, for every $j, G_{j}=t_{j} Y_{j}$ is a best reply to the corresponding provisions $G_{i} \forall i \neq j$.

The set of necessary equilibrium conditions of the model can be summarized as follows:

Migration equilibrium. The indifferent households between adjacent municipalities are at the actual 'border' of every municipality; i.e., (5) holds with equality only for $y_{j}$ and $\overline{y_{j}}$. All households in between strictly prefer municipality $j$ to any other municipality.

Majority voting equilibrium. The tax rate in every municipality is chosen such that equation (7) holds, and the corresponding provisions of the publicly provided good are corresponding best replies.

Housing market equilibrium. Equation (3) holds in every municipality.

This results in a system of $3 J-1$ equations (note that there are only $J-1$ indifferent households) and $3 J-1$ unknowns (housing prices, public provision levels and border households). system, we maintain the hypothesis of perfect foresight for simplicity. 
Neither existence nor uniqueness can be established, as is usually the case in tax competition problems. Without further assumptions on preferences, it is not possible to analytically determine the effect of spillovers and imperfect rivalry on equilibrium outcomes. For the case of Stone-Geary preferences, however, we solve the model for various combinations of $\sigma$ and $\rho$ numerically and quantify the inefficiencies in Section 3.

\subsection{Efficiency benchmark}

To identify the inefficiencies from decentralization, we formulate a first-best version of our model. A planner maximizes a social welfare function by assigning the population across municipalities and choosing the efficient level of public provision and taxation. The social planner has access to revenue-neutral individual transfers $r(y)$ in addition to uniform head taxes in every municipality $T_{j}$, which in combination constitute individualized lump-sum taxation. We specify that the sum of transfer payments is zero in order to allow for a clean separation between taxes used to finance the publicly provided good and for the revenue-neutral redistribution of income. In order to compare the outcome with the decentralized equilibrium and to be prepared for the Decomposition of the welfare loss, we additionally include income taxes as a policy instrument, even though they will obviously not be used if lump-sum taxation is available.

The indirect utility function of a household with exogenous income $y$ living in municipality $j$ is a generalized version of (4) and is given by

$$
\begin{aligned}
V\left(p_{j}, t_{j}, T_{j}, g_{j} ; y, r(y)\right)=\max _{x, h} U\left(x^{j}, h^{j}, g_{j}\right) \\
\text { s.t. } y\left(1-t_{j}\right)+r(y)-T_{j}=x^{j}+p_{j} h^{j},
\end{aligned}
$$

where $y\left(1-t_{j}\right)+r(y)-T_{j}$ is the after-tax income of the household. For brevity, we define $V^{j}(y) \equiv V\left(p_{j}, t_{j}, T_{j}, g_{j} ; y, r(y)\right)$. Borrowing notation from Calabrese et al. (2012), we write the 
first-best problem as

$$
\begin{gathered}
\max _{a_{j}(y), r(y), R, t_{j}, T_{j}, p_{j}, g_{j}} \sum_{j=1}^{J}\left\{\int_{\underline{y}}^{\bar{y}} \omega(y) V^{j}(y) a_{j}(y) f(y) \mathrm{d} y+\omega_{R}\left(\frac{R}{J}+\int_{0}^{p_{j}} H^{S}(z) \mathrm{d} z\right)\right\} \\
\text { s.t. } \quad g_{j}=\frac{t_{j} Y_{j}+T_{j} N_{j}+\sigma \sum_{i \neq j}\left(t_{i} Y_{i}+T_{i} N_{i}\right)}{\left(N_{j}+\nu \sum_{i \neq j} N_{i}\right)^{\rho}} \forall j \\
H^{S}\left(p_{j}\right)=\int_{\underline{y}}^{\bar{y}} h^{j}(y) a_{j}(y) f(y) \mathrm{d} y \quad \forall j \\
R+\int_{\underline{y}}^{\bar{y}} r(y) f(y) \mathrm{d} y=0,
\end{gathered}
$$

where $\omega(y)$ is the welfare weight placed on households with income $y$, and $\omega_{R}$ is the welfare weight that relates the monetary transfer $R$ to the absentee landlords (which may be negative) and their economic rent into social welfare 17 The choice variable $a_{j}(y) \in[0,1]$ represents the share of the population with income $y$ that resides in municipality $j$, with $\sum_{j} a_{j}(y)=1$. For all income segregating equilibria, $a_{j}(y)=1$ if $y \in\left(\underline{y_{j}}, \overline{y_{j}}\right)$ and $a_{i \neq j}(y)=0$.

We assign the following Lagrange multipliers: $\lambda_{j}$ for the budget constraint of the municipality (10), $\eta_{j}$ for housing market clearing (11), and $\Omega$ for the revenue-neutrality of the income transfers (12).

The marginal social value of adding a unit measure of the population with income $y$ to municipality $j, M S V_{j}(y)$, is given by the derivative of the Lagrangian with respect to $a_{j}(y) f(y) \cdot 18$

$$
\begin{aligned}
M S V_{j}(y)= & \omega(y) V^{j}(y)+\left(\lambda_{j}+\sigma \sum_{i \neq j} \lambda_{i}\right)\left[t_{j} y+T_{j}\right]+\eta_{j} h^{j}(y) \\
& -\rho\left\{\lambda_{j} g_{j}\left(N_{j}+\nu \sum_{i \neq j} N_{i}\right)^{\rho-1}+\sigma \sum_{i \neq j} \lambda_{i} g_{i}\left(N_{i}+\nu \sum_{k \neq i} N_{k}\right)^{\rho-1}\right\} .
\end{aligned}
$$

For income-segregating equilibria, which are the focus in this paper, the social planner chooses the border household $y_{i, j}^{\text {border }}$ between any two adjacent municipalities $i$ and $j$ such that

\footnotetext{
${ }^{17}$ Our treatment of housing rents is the same as in Calabrese et al. (2012). Alternatively, one could, for example, assume that housing is collectively owned by the local population. While this would pose no problem for the first-best setting, it would require a redistribution scheme for (endogenous) housing profits in the decentralized model. Note that setting the welfare weight on the landlords to zero would lead to a complete expropriation of the landlords (the optimal transfer would be minus infinity). One could limit this by forcing $R=0$, but this would lead to a non-closed model that would not be suitable for normative analysis.

${ }^{18}$ Note that the $M S V_{j}(y)$ is generally nonzero, because the control variable $a_{j}(y)$ is at a corner solution for equilibria characterized by income segregation (either zero or one); the complementary slackness conditions have been omitted in 13 for notational convenience.
} 
$M S V_{i}\left(y_{i, j}^{\text {border }}\right)=M S V_{j}\left(y_{i, j}^{\text {border }}\right)$. All poorer (richer) households have a strictly higher marginal social welfare in the poorer (richer) municipality when compared to the other municipality.

Denoting partial derivatives by subscripts, the first-order conditions with respect to $r(y)$ and $R$ can be combined to

$$
\sum_{j=1}^{J} \omega(y) V_{y}^{j}(y) a_{j}(y)+\sum_{j=1}^{J} \eta_{j} h_{y}^{j}(y) a_{j}(y)=\omega_{R} .
$$

The remaining first-order conditions are

$$
\begin{array}{ll}
T_{j}: & \int_{\underline{y}}^{\bar{y}} \omega(y) V_{T}^{j}(y) a_{j}(y) f(y) \mathrm{d} y+N_{j}\left(\lambda_{j}+\sigma \sum_{i \neq j} \lambda_{i}\right)+\eta_{j} \int_{\underline{y}}^{\bar{y}} h_{T}^{j}(y) a_{j}(y) f(y) \mathrm{d} y=0 \\
t_{j}: & \int_{\underline{y}}^{\bar{y}} \omega(y) V_{t}^{j}(y) a_{j}(y) f(y) \mathrm{d} y+Y_{j}\left(\lambda_{j}+\sigma \sum_{i \neq j} \lambda_{i}\right)+\eta_{j} \int_{\underline{y}}^{\bar{y}} h_{t}^{j}(y) a_{j}(y) f(y) \mathrm{d} y=0 \\
p_{j}: & \int_{\underline{y}}^{\bar{y}} \omega(y) V_{p}^{j}(y) a_{j}(y) f(y) \mathrm{d} y+\omega_{R} H^{S}\left(p_{j}\right)+\eta_{j}\left[\int_{\underline{y}}^{\bar{y}} h_{p}^{j}(y) a_{j}(y) f(y) \mathrm{d} y-H_{p}^{S}\left(p_{j}\right)\right]=0 \\
g_{j}: & \int_{\underline{y}}^{\bar{y}} \omega(y) V_{g}^{j}(y) a_{j}(y) f(y) \mathrm{d} y-\lambda_{j}\left(N_{j}+\nu \sum_{i \neq j} N_{i}\right)^{\rho}+\eta_{j} \int_{\underline{y}}^{\bar{y}} h_{g}^{j}(y) a_{j}(y) f(y) \mathrm{d} y=0
\end{array}
$$

Together with the constraints (10)-12, conditions (13)-18 represent the full model ${ }^{19}$ In the first-best equilibrium, i.e., with individualized transfers and head taxes, it follows that $t_{j}=0$ and 16 drops out. Constrained versions of the model can be derived by denying the planner access to individualized transfers and head taxes, by allowing households to choose their preferred municipality, and by allowing municipalities to decide on the desired level of public provision by majority vote. Such second-best versions are considered in Section 4.2 .

We are now set to investigate the welfare loss from decentralization. Because we take the view of a fully informed social planner, decentralization necessarily leads to a welfare loss, as it amounts to placing constraints on the first-best problem. We abstract from the welfare gains from decentralization, which may more than offset the costs. There are three sources that contribute to the aggregate welfare loss when moving from the first-best to the fully decentralized solution.

\footnotetext{
${ }^{19}$ This set of efficiency and equilibrium conditions are valid for interior solutions. For the problem at hand, however, some parameter combinations would give rise to a corner solution. For example, if rivalry and spillovers are (very) low and if the housing supply elasticity is sufficiently high or the municipality sizes sufficiently heterogeneous, it might be optimal for the social planner to leave one municipality empty (just as we encountered for the decentralized case). In such cases, [13 - 18 would continue to hold for the occupied jurisdictions.
} 
(1) Imperfect redistribution. This is a consequence of the (standard) assumption that in the decentralized setting, lump-sum taxes are not available such that income redistribution only takes place via public provision financed by non-benefit taxes.

(2) Inter-municipal free-riding. There is an underprovision of the publicly provided good because the local median voter does not consider the benefit accruing to other municipalities. In our model, this inefficiency includes the inefficiency from voting per se, i.e., the welfare loss that arises from setting the tax rate by the median voter rather than a regional social planner. We show in our numerical application that this effect is small.

(3) Inefficient allocation of the population. This is due to the free mobility of the households and can be interpreted as intra-municipal free-riding, as households seek to consume more of the public good than the amount they contribute in the form of income tax payments.

Calabrese et al. (2012) call the inefficiency in (3) the "jurisdictional choice externality" (JCE), and we will make use of this term for the remainder of the paper. The $J C E_{j}(y)$ that a household with income $y$ imposes on society when being added to municipality $j$ can be obtained by subtracting the private component from the MSV (13) and substituting (10):

$$
\begin{aligned}
J C E_{j}(y) & =\left(\lambda_{j}+\sigma \sum_{i \neq j} \lambda_{i}\right)\left(t_{j} y+T_{j}\right)+\eta_{j} h^{j}(y) \\
& -\rho\left(\lambda_{j} \frac{t_{j} Y_{j}+T_{j} N_{j}+\sigma \sum_{i \neq j} t_{i} Y_{i}+T_{i} N_{i}}{N_{j}+\nu \sum_{i \neq j} N_{i}}+\sigma \sum_{i \neq j} \lambda_{i} \frac{t_{i} Y_{i}+T_{i} N_{i}+\sigma \sum_{k \neq i} t_{k} Y_{k}+T_{k} N_{k}}{N_{i}+\nu \sum_{k \neq i} N_{k}}\right) .
\end{aligned}
$$

The first term of the JCE is the (positive) social value of the tax payment by this household. This value accrues not only to residents in municipality $j$ but also to those in all other municipalities due to the spillovers. The third term reflects the aggregate congestion cost, again arising in all municipalities, and is negative. With zero congestion, this term drops out.

The second term measures the social cost or benefit of adding another household to the housing market and can be positive or negative. To gain an intuition about the nature of this last source of inefficiency, we solve (17) for $\eta_{j}$ :

$$
\eta_{j}=\frac{\int_{\underline{y}}^{\bar{y}} \omega(y) V_{p}^{j}(y) a(y)_{j} f(y) \mathrm{d} y+\omega_{R} H^{S}\left(p_{j}\right)}{H_{p}^{S}\left(p_{j}\right)-\int_{\underline{y}}^{\bar{y}} h_{p}^{j}(y) a_{j}(y) f(y) \mathrm{d} y} .
$$


Under regular assumptions about the demand and the supply of housing, the denominator is positive, whereas the two terms in the numerator have opposite signs. If the welfare weight placed on the absentee landlords is sufficiently small, it follows that $\eta_{j}<0$, and vice versa. Intuitively, if the landlords do not contribute much value to social welfare, adding population to municipality $j$ increases the housing price for all residents in that municipality, which is only partially offset by social benefits in the form of higher economic rents for the landlords 20 In a first-best environment where the social planner has access to individualized lump-sum taxation, chooses the level of local provision of public goods and assigns the population across municipalities, the allocation of the population is efficient such that $\eta_{j}=0 \forall j$ (see Calabrese et al. 2012, Prop. 3). A version of the proof using our setting (i.e., income rather than property taxation) is included in Appendix A1.

We can now state our first proposition:

\section{Proposition 1. Jurisdictional choice externality (JCE)}

(i) In a first-best environment where the social planner has access to individualized lump-sum taxation, chooses the level of local provision of public goods and assigns the population across municipalities, the JCE for a publicly provided private good is zero.

(ii) In the presence of positive spillovers and/or imperfect congestion, the JCE is generally nonzero even in first-best. In this case, the sign of the JCE is determined by the relative strength of spillovers and congestion.

(iii) If revenue is raised via an income tax, the JCE increases with household income, provided that the housing market externality is not too negative.

(iv) The social planner allocates the population such that the JCE associated with the border household is equalized across the relevant municipalities: $J C E_{j}\left(\tilde{y}_{j, j+1}\right)=J C E_{j+1}\left(\tilde{y}_{j, j+1}\right)$.

(Proof in Appendix A2.)

Intuitively, adding a household to a municipality increases both public production and congestion. Whether the net effect is positive depends on the available policy instruments

\footnotetext{
${ }^{20}$ To avoid a possible confusion, note that $\eta_{j}$ is not a measure for the housing price. The planner assigns people across jurisdictions. $\eta_{j}$ measures to what extent this assignment differs from the assignment that households themselves would choose.
} 
(head vs. income taxes), the nature of the public good, the income of the household, and the average income and population size of the municipality to which the household is added. With income taxation, adding a rich household to a municipality increases public consumption by more than adding a poor household, all else equal. Note, finally, that due to the presence of spillovers, the JCE can be positive (or negative) for all municipalities, such that the inefficiency of the locational choice is due to the difference in the JCE's of the relevant municipalities, not their absolute values.

We now turn to inefficiency (2), the inter-municipal free-riding on the provision of the publicly provided good elsewhere. Conditions (14), (15) and (18) can be combined to obtain a relatively complicated optimality condition (see in the Appendix). Under first-best conditions, this expression can be simplified, which leads to the following proposition:

\section{Proposition 2. Public production}

(i) In a first-best environment where $t_{j}=\eta_{j}=0$, the following expression provides a modified Samuelson condition that allows for spillovers and imperfect rivalry in consumption:

$$
\int_{\underline{y}}^{\bar{y}} \frac{V_{g}^{j}(y)}{V_{y}^{j}(y)} a_{j}(y) f(y) d y=\frac{\left(N_{j}+\nu \sum_{i \neq j} N_{i}\right)^{\rho}}{1+\sigma(J-1)} .
$$

(ii) In the first-best equilibrium, the marginal value of public funds is equalized across municipalities:

$$
\lambda_{j}=\lambda=\frac{\omega_{R}}{1+\sigma(J-1)} \quad \forall j
$$

(Proof in Appendix A3.)

The LHS of (21) is the aggregate marginal rate of substitution between public consumption and the numeraire, and the RHS is the marginal rate of transformation. For the special case of a publicly provided private good $(\rho=1$ and $\sigma=\nu=0)$, the Samuelson condition simplifies to the familiar form of

$$
\int_{\underline{y}}^{\bar{y}} \frac{V_{g}^{j}(y)}{V_{y}^{j}(y)} a_{j}(y) f(y) \mathrm{d} y=N_{j},
$$


where $N_{j}$ equals the marginal rate of transformation between the publicly provided good and the numeraire.

Condition (22) states that the marginal value of public funds is equalized across municipalities, and that the greater the inter-municipal spillovers, the more resources are optimally used for the production of the publicly provided good (such that $\lambda$ becomes smaller; note that with concave preferences, $\lambda_{j}$ has to decrease in $g_{j}$ ). This is intuitive, since spillovers increase the benefit of public provision without increasing its cost, leading to a higher optimal level of public provision, all else being equal.

In the fully decentralized equilibrium, the median voter determines the amount of public provision from (7). There is no closed-form solution for the level of public provision in this general form. In the next section, we impose some structure on the preferences, which allows us to derive expressions for the contribution to the publicly provided good in the social optimum and the decentralized equilibrium.

\section{Numerical implementation}

In this section, we carry out a numerical illustration of our theory 21 We derive analytical results for the resulting equilibrium conditions and the degree of public under-provision due to inter-municipal free-riding. Last, we numerically compute the distribution of households and the level of public and private consumption in the decentralized equilibrium, for varying degrees of spillovers and rivalry in consumption.

\subsection{Equilibrium conditions}

We define preferences using a Stone-Geary utility function, which complies with the sufficient conditions for income segregation as discussed in Schmidheiny (2002):

$$
U_{j}\left(x^{j}, h^{j}, g_{j}\right)=\alpha \ln \left(g_{j}-\beta_{g}\right)+\gamma \ln \left(h^{j}-\beta_{h}\right)+(1-\alpha-\gamma) \ln \left(x^{j}-\beta_{x}\right),
$$

\footnotetext{
${ }^{21}$ We would like to stress that this is not an empirical application. A calibration of the model to actual data would require the use of an additional heterogeneity, other than income, because in practice pure sorting based on income is never observed.
} 
where $\beta_{g}, \beta_{h}$ and $\beta_{x}$ are subsistence levels for $g_{j}, h^{j}$ and $x^{j}$, respectively, and $\alpha, \gamma$ and $1-\alpha-\gamma$ (all of which are between zero and one) are the corresponding preference parameters. Solving the consumer's problem leads to a demand function for housing and the numeraire good of $h^{j}(y)=\beta_{h}+\gamma \frac{y\left(1-t_{j}\right)+r(y)-T_{j}-p_{j} \beta_{h}-\beta_{x}}{(1-\alpha) p_{j}}$ and $x^{j}(y)=y\left(1-t_{j}\right)+r(y)-T_{j}-p_{j} h^{j}(y)$, respectively, where $r(y)$ is the individual lump-sum transfer for household $y$, and $T_{j}$ is the municipalityspecific lump-sum head tax to finance public provision; if these instruments are not available (as it is the case in the fully decentralized equilibrium), they are set to zero.

The indirect utility function is given by

$$
\begin{aligned}
V\left(p_{j}, T_{j}, t_{j}, g_{j} ; y\right)= & (1-\alpha) \ln \left[y\left(1-t_{j}\right)+r(y)-T_{j}-p_{j} \beta_{h}-\beta_{x}\right] \\
& +\alpha \ln \left(g_{j}-\beta_{g}\right)-\gamma \ln \left(p_{j}\right)+c
\end{aligned}
$$

with $c \equiv(1-\alpha-\gamma) \ln \left(\frac{1-\alpha-\gamma}{1-\alpha}\right)+\gamma \ln \left(\frac{\gamma}{1-\alpha}\right)$. The derivatives of the indirect utility function and the set of first-best efficiency conditions can be found in Table A1 in the Appendix.

The housing market clearing condition (3) is defined by

$$
L_{j} p_{j}^{\theta}-\int_{\underline{y_{j}}}^{\overline{y_{j}}}\left(\gamma \frac{y\left(1-t_{j}\right)+r(y)-T_{j}-p_{j} \beta_{h}-\beta_{x}}{(1-\alpha) p_{j}}+\beta_{h}\right) f(y) \mathrm{d} y=0,
$$

where $L_{j} p_{j}^{\theta}$ is the housing supply function, $L_{j} \in[0,1]$ is the relative land size of municipality $j$ (i.e., we normalize aggregate land to unity), and $\theta$ is the price elasticity of the housing supply.

In the fully decentralized setting (where $r(y)=T_{j}=0$ ), the household that is indifferent between the two adjacent municipalities $j$ and $j-1$ is defined by

$$
\widetilde{y}_{j-1, j}=\frac{\left(p_{j} \beta_{h}+\beta_{x}\right) p_{j-1}^{\frac{\gamma}{1-\alpha}}\left(g_{j}-\beta_{g}\right)^{\frac{\alpha}{1-\alpha}}-\left(p_{j-1} \beta_{h}+\beta_{x}\right) p_{j}^{\frac{\gamma}{1-\alpha}}\left(g_{j-1}-\beta_{g}\right)^{\frac{\alpha}{1-\alpha}}}{\left(1-t_{j}\right) p_{j-1}^{\frac{\gamma}{1-\alpha}}\left(g_{j}-\beta_{g}\right)^{\frac{\alpha}{1-\alpha}}-\left(1-t_{j-1}\right) p_{j}^{\frac{\gamma}{1-\alpha}}\left(g_{j-1}-\beta_{g}\right)^{\frac{\alpha}{1-\alpha}}}
$$

\subsection{Public production}

For the median income household in municipality $j, y_{j}^{m}$, the first-order condition with respect to the tax rate (7) derived from the voter's maximization problem becomes

$$
\frac{(1-\alpha) y_{j}^{m}}{y_{j}^{m}\left(1-t_{j}\right)-p_{j} \beta_{h}-\beta_{x}}=\frac{\alpha Y_{j}}{t_{j} Y_{j}+\sigma \sum_{i \neq j} G_{i}-\left(N_{j}+\nu \sum_{i \neq j} N_{i}\right)^{\rho} \beta_{g}}
$$


We can solve (28) for $t_{j} Y_{j}$, which by the municipality budget constraint defines municipality $j$ 's contribution to the publicly provided good for an interior solution of $t_{j}{ }^{22}$

$$
G_{j}^{d e c}=\left(N_{j}+\nu \sum_{i \neq j} N_{i}\right)^{\rho} \beta_{g}+\frac{\alpha}{1-\alpha}\left(Y_{j}^{d i s p}-N_{j} \frac{E\left[y_{j}\right]-y_{j}^{m}}{y_{j}^{m}}\left(p_{j} \beta_{h}+\beta_{x}\right)\right)-\sigma \sum_{i \neq j} G_{i}
$$

where $Y_{j}^{\text {disp }} \equiv N_{j} \cdot\left(E\left[y_{j}\right]\left(1-t_{j}\right)-p_{j} \beta_{h}-\beta_{x}\right)$ is the aggregate disposable municipality income and $E\left[y_{j}\right]$ is the mean income, such that $\left(E\left[y_{j}\right]-y_{j}^{m}\right) / y_{j}^{m}$ measures the right-skewness of the income distribution.

The contribution of municipality $j$ to the publicly provided good is determined by three terms. The first term is the subsistence level of the publicly provided good, adjusted for the population that has access to the domestic market and corrected for congestion. The second term describes the median voter's demand for public provision in excess of the subsistence level. Finally, the optimal level of public provision in the municipality is reduced by what spills over from the other municipalities (third term). In the absence of spillovers, this term drops out. ${ }^{23}$

The contribution to the publicly provided good increases in the preference parameter: The higher is $\alpha$, the more is spent on the publicly provided good. If $\alpha$ is zero, public provision only takes place to satisfy the subsistence level, which may be partially or fully met by the spillovers from the other municipalities. If the third term exceeds the sum of the first and second terms, the municipality free-rides completely on the public provision of the other municipalities. Last, note that $G_{j}=t_{j} Y_{j}$, with $t_{j}$ chosen by the median voter, is limited by $0 \leq t_{j} \leq 1$.

The Pareto-optimal counterpart to 29 can be deduced from the Samuelson condition (21)

\footnotetext{
${ }^{22}$ To help the reader with the derivation of 29 , note that 28 solves to $t_{j} Y_{j} \equiv G_{j}^{d e c}=$ $\left(N_{j}+\nu \sum_{i \neq j} N_{i}\right)^{\rho} \beta_{g}+\frac{\alpha}{1-\alpha} \frac{Y_{j}}{y_{j}^{m}}\left(y_{j}^{m}\left(1-t_{j}\right)-p_{j} \beta_{h}-\beta_{x}\right)-\sigma \sum_{i \neq j} G_{i}$. Substitute $Y_{j}=N_{j} E\left[y_{j}\right]$ in the second term, bring $\frac{E\left[y_{j}\right]}{y_{j}^{m}}$ inside the bracket, and add and subtract $\left(p_{j} \beta_{h}+\beta_{x}\right)$ to obtain

$$
\frac{\alpha}{1-\alpha} N_{j}(\underbrace{E\left[y_{j}\right]\left(1-t_{j}\right)-\left(p_{j} \beta_{h}+\beta_{x}\right)}_{=Y_{j}^{\text {disp }} / N_{j}} \underbrace{+\left(p_{j} \beta_{h}+\beta_{x}\right)-E\left[y_{j}\right] / y_{j}^{m} \cdot\left(p_{j} \beta_{h}+\beta_{x}\right)}_{=-\left(E\left[y_{j}\right]-y_{j}^{m}\right) / y_{j}^{m} \cdot\left(p_{j} \beta_{h}+\beta_{x}\right)}) .
$$

${ }^{23}$ Even in the case without spillovers, the supply of the publicly provided good depends indirectly on the other municipalities' choices, which affect the population distribution and therefore determine $N_{j}$ and $Y_{j}$ along with the housing price $p_{j}$ and the median voter $y_{j}^{m}$.
} 
derived for the benchmark model. Using our functional forms, it is given by ${ }^{24}$

$$
G_{j}^{P O}=\left(N_{j}+\nu \sum_{i \neq j} N_{i}\right)^{\rho} \beta_{g}+\frac{\alpha}{1-\alpha} Y_{j}^{d i s p}(1+\sigma(J-1))-\sigma \sum_{i \neq j} G_{i} .
$$

One way to assess the consequence of free-riding is to evaluate (29) and (30) for a given distribution of the population, and a given level of public production in municipalities $i \neq j$ (which is of course not the case in the different equilibria). Holding these values fixed, 29) and 30 differ by their respective middle terms only:

$$
G_{j}^{P O}-G_{j}^{d e c}=\frac{\alpha}{1-\alpha}\left[Y_{j}^{d i s p} \cdot \sigma(J-1)+N_{j} \frac{E\left[y_{j}\right]-y_{j}^{m}}{y_{j}^{m}}\left(p_{j} \beta_{h}+\beta_{x}\right)\right]
$$

Under regular conditions where $E\left[y_{j}\right] \geq y_{j}^{m},(31)$ is positive, implying public under-provision in the decentralized setting. Decentralized public provision is only efficient for the special case of publicly provided private goods and a symmetric income distribution.

In our numerical model, we calculate public consumption at various steps of decentralization, thus taking into account the population distribution and the public production in other municipalities (see bottom panel in Figure 7). The decentralized setting of taxes has by far the largest effect on the decrease in public consumption, relative to constrained redistribution and inefficient residential choice.

\subsection{Decentralized equilibrium}

A decentralized equilibrium requires that housing markets clear ( $J$ housing prices solve $J$ equations (26)), that tax rates constitute a majority voting equilibrium ( $J$ median voters choose public provision levels according to $J$ equations (29), and that the indifferent households are at the municipalities' borders $(J-1$ indifferent households are determined by $J-1$ equations (27)). Note that even for the most simple setup, this set of equilibrium conditions cannot be solved analytically. In this subsection, we provide quantitative results from a numerical implementation of the decentralized equilibrium for varying values of spillovers and congestion.

\footnotetext{
${ }^{24}$ To derive 30 , substitute the partial derivatives of the indirect utility function (described in Table A1) into 21, use that $t_{j}=0$ in first-best, that the aggregate disposable income in $j, Y_{j}^{\text {disp }}$, is given by $N_{j} \int_{y}\left(y+r(y)-T_{j}-p_{j} \beta_{j}-\beta_{x}\right) a_{j}(y) f(y) \mathrm{d} y$, and solve this expression for $g_{j}$. To calculate the corresponding efficient production of the publicly provided good, solve (2) for $G_{j}$ and plug in the previous expression for $g_{j}$.
} 
We chose to use an abstract model economy, since calibration of any kind would imply that only a narrow range of combinations of $\rho$ and $\sigma$ could be used to describe the observed situation. Thus, our setup allows us to assess the welfare consequences of decentralized provision for different characteristics of the publicly provided good, and it eases calculation and the representation of results. Another issue of a calibrated model would be to cope with the progressive nature of income taxation.

There are $J=2$ municipalities in our model economy. Household income is uniformly distributed between $\underline{y}=1$ and $\bar{y}=2$. We further assume that households have access to the other municipality's public provision to the same degree as there are spillovers; i.e., we set $\nu=\sigma$. Aggregate land is normalized to 1 , and both municipalities are of equal size. Since municipalities do not differ ex ante, we can assume without loss of generality that municipality 1 is inhabited by the poor and municipality 2 by the rich households. Thus, $\widetilde{y}_{1,2}=\overline{y_{1}}=\underline{y_{2}}$ is the indifferent household.

Table 1: Parameter values for the baseline calibration.

\begin{tabular}{lllllllllll}
\hline Parameter & $\alpha$ & $\beta_{x}$ & $\beta_{h}$ & $\beta_{g}$ & $\gamma$ & $\nu$ & $\theta$ & $L_{1}$ & $\underline{y}$ & $\bar{y}$ \\
\hline Value & 0.2 & 0.2 & 0.2 & 0 & 0.1 & $\sigma$ & 3 & 0.5 & 1 & 2 \\
\hline
\end{tabular}

Definition of parameters. $\alpha$ : preference for publicly provided good; $\beta_{x}$ : subsistence level (SL) of the numeraire; $\beta_{h}$ : SL of housing; $\beta_{g}$ : SL of the publicly provided good; $\gamma$ : housing preference; $\nu$ : neighborhood parameter (access to publicly provided good in the other municipality), set to equal $\sigma ; \theta$ : price elasticity of housing supply; $L_{1}$ : (relative) land size of municipality $1\left(L_{2}=1-L_{1}\right)$; $y$ : lower bound of income distribution; $\bar{y}$ : upper bound of income distribution.

The values of the remaining parameters are given in Table 1. The parameters are set such that the subsistence levels account for $40 \%$ of the poorest household's income if the housing prices were 1 (the price of the numeraire good is unity by construction). We choose moderate levels of the relative preference parameters for the publicly provided good and housing ( $\alpha=0.2$ and $\gamma=0.1$, respectively), which implies that households optimally spend most of their disposable income on the numeraire good. $\theta=3$ is a common value of the housing price elasticity (see e.g. Schmidheiny 2006b). In section 4.3, we discuss a series of sensitivity checks in which we vary these parameters by $20 \%$ in each direction.

Figure 1 shows the indifferent border-household $\widetilde{y}_{1,2}$ as a function of $\sigma$ and $\rho$. With a uniform distribution of income, the population share is given by the difference between $\widetilde{y}_{1,2}$ and $\underline{y}=1$ 


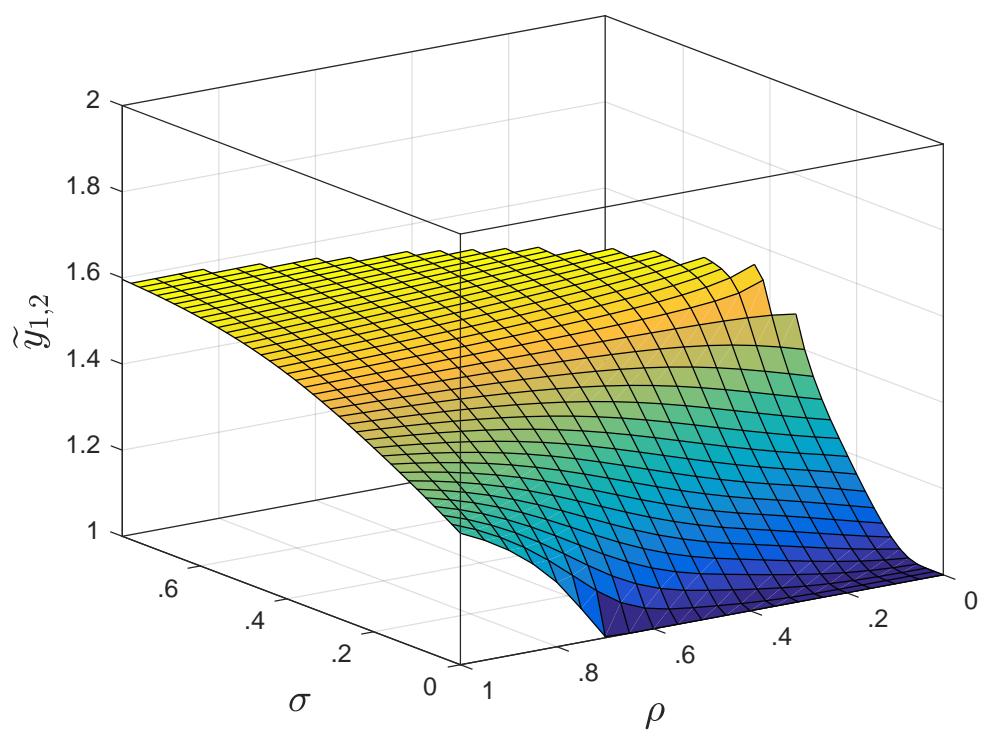

Figure 1: Border household in the decentralized equilibrium, for various combinations of spillovers $(\sigma)$ and congestion $(\rho)$.

and $\bar{y}=2$ for municipality 1 and 2, respectively. Figure 2 shows the resulting housing prices, tax rates, public production and public consumption. Equilibrium values for specific values of $\sigma$ and $\rho$ are given in Table A3 in the Appendix. For the special case of a publicly provided private good, the poorest $30 \%$ of the population live in municipality 1 , whereas the richest $70 \%$ of the population reside in municipality 2 . The rich municipality exhibits higher public consumption in exchange for a higher housing price and higher income taxes ${ }^{25}$

In general, decreasing the degree of congestion leads to a more uneven distribution of the population among municipalities due to economies of scale. Intuitively, with a low degree of rivalry, the increasing returns to scale from public provision dominate the moving decision, since a larger tax base translates into a higher consumption level for all residents ${ }^{26}$

An increase in spillovers results in a more equal distribution of the population (Figure 1 and to a convergence in public production and consumption (bottom panels in Figure 2). Housing prices are higher in the rich municipality for spillover levels of up to approximately

\footnotetext{
${ }^{25}$ Since municipalities differ along three dimensions, there are three different possible trade-offs that may emerge: (i) Higher level of public provision in exchange for a higher housing price and higher taxes; (ii) a lower housing price in exchange for higher taxes and a lower level of public provision; and (iii) lower taxes in exchange for a higher housing price and a lower level of public provision. Our findings for the publicly provided private good are consistent with the results in Schmidheiny (2006b), but as is evident from Figure 2, this is not a general result.

${ }^{26}$ Consider combinations of $\sigma=0$ and $\rho<1$, which correspond to the surface in front and to the right in Figure 1. If rivalry in consumption is low enough (in our case approximately 0.65), households choose to reside in only one municipality, leaving the other empty.
} 

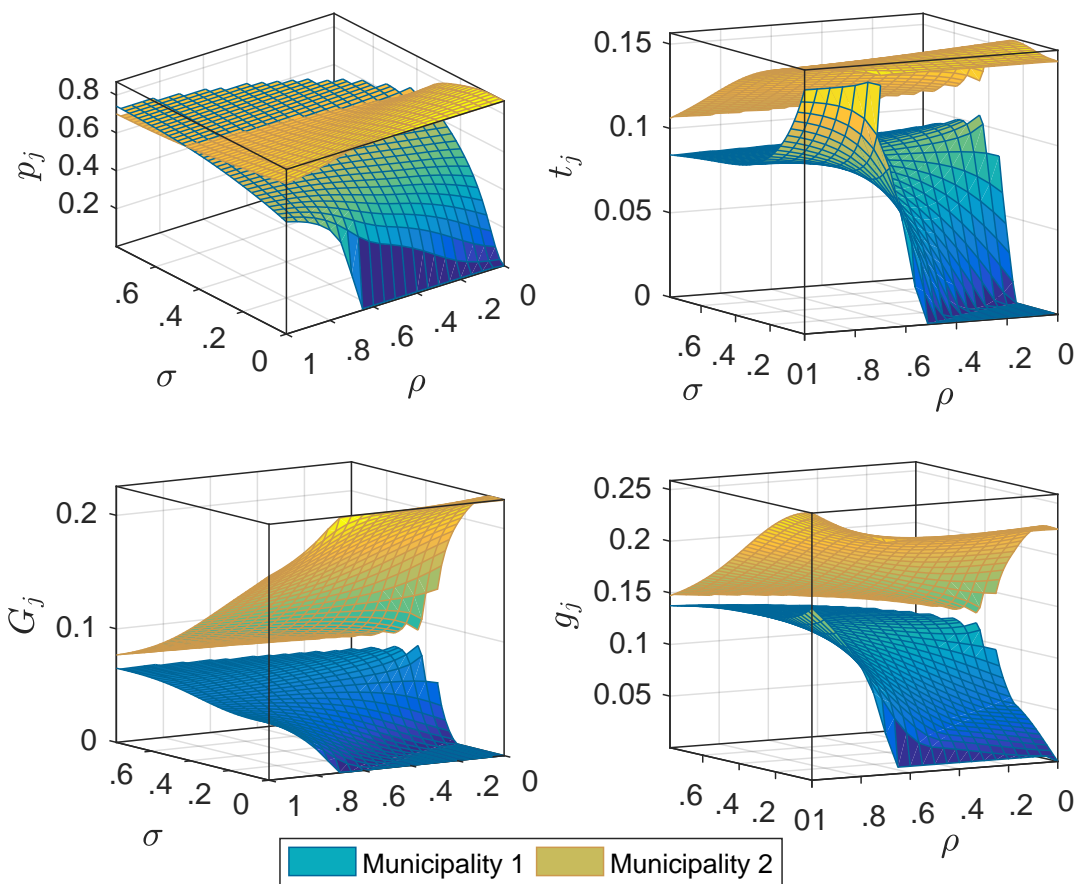

Figure 2: Municipality characteristics in the decentralized equilibrium, for various combinations of spillovers $(\sigma)$ and rivalry in consumption $(\rho)$ : Housing price $p_{j}$, tax rate $t_{j}$, production $G_{j}$, and consumption $g_{j}$.

0.5, whereas for larger levels, prices are higher in the poor municipality. Income tax rates, however, are higher in the rich municipality for all combinations of spillovers and congestion. There is a range of parameter combinations for which the tax rate in the poor municipality is zero, but the municipality is not empty. In these cases, the poor municipality completely free-rides on the public provision of the rich municipality.

We find no stable equilibria if spillovers are high and/or congestion is low enough, and we are not able to identify income separating equilibria for $\sigma \geq 0.8$ independent of the value of $\rho$. Intuitively, high spillovers and low levels of congestion reduce the degree of tax competition in the sense that the income differences between municipalities become less pronounced. For sufficiently large spillovers, the equilibrium is no longer characterized by income segregation.

\section{Welfare analysis}

Because we abstract from the benefits of decentralization (by imposing complete information and abstracting from rent-seeking activities), decentralizing public provision leads to a welfare loss by construction in our model. In this section, we decompose this welfare loss into inefficient 
redistribution, the inefficient choice of tax rates, and the inefficient choice of residence. We further illustrate how the individual components depend on spillovers and congestion.

Our efficiency benchmark is based on the theoretical model described in Section 2.2. The planner maximizes a utilitarian social welfare function (SWF) with welfare weights for all households set to unity. We restrict our attention to income-segregating equilibria ${ }^{27}$ Our approach differs from Calabrese et al. (2012), who choose the weights of their welfare function implicitly such that the individual transfers are optimally zero. Their implicit SWF places substantially more weight on the rich than on the poor.

To match our model with reality where governments usually cannot enforce transfers from or to the landlords, we choose $\omega_{R}$ such that $\mathrm{R}=0$ is optimal for the 'semi-public' good case of $\sigma=0.3$ and $\rho=0.5{ }^{28}$ To find the global maximum, we use a grid search over $\widetilde{y}_{1,2}$ (thereafter $y^{\text {border }}$ for the two-municipality-case) to determine the border household. Our analysis reveals that for almost all combinations of $\sigma$ and $\rho$ there are three saddle points that comply with the first-order conditions derived in Section 2.2. A welfare minimum, one local welfare maximum, and one global maximum. The shape of the SWF for varying levels of $y^{\text {border }}, \sigma$ and $\rho$ is displayed in Figures A1 and A2 in the Appendix.

\subsection{Welfare loss from decentralization}

Figure 3 shows the difference between the value of the SWF in the first-best equilibrium and in the fully decentralized equilibrium, for different combinations of $\sigma$ and $\rho$. The welfare loss from decentralization increases with the degree of spillovers and decreases with rivalry in consumption over much of the parameter space, and it has a maximum for a combination of intermediate levels of spillovers and low rivalry in consumption. The underlying reason for these relationships is that making the good more public in nature leads to a mechanical increase in welfare due to greater benefits associated with a unit of the public good, but also to a greater scope for inefficiency from decentralization due to inter-municipal free-riding (spillovers) and an inefficient allocation of the population (rivalry).

\footnotetext{
${ }^{27}$ This implies that the distribution of households boils down to a one-dimensional decision for the planner: By determining the border household, all poorer (richer) households are located in municipality 1 (2). Formally, $a_{1}(y)=1 \forall y<y^{\text {border }}$ and $a_{2}(y)=1 \forall y>y^{\text {border }}$, whereas all other values of $a$ are zero.

${ }^{28}$ Given our parameter choices, this results in $\omega_{R}=0.444$. Note that given our parameters, the housing rents are relatively small, such that the results are not very sensitive to the choice of $\omega_{R}$.
} 


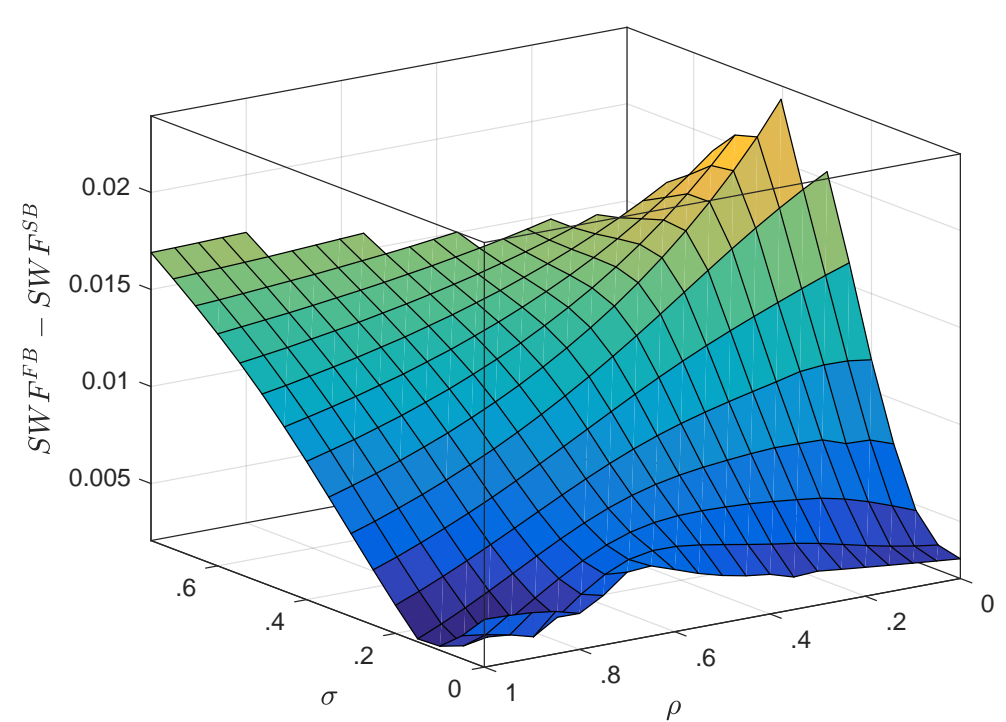

Figure 3: Difference in the value of the Social Welfare Function (SWF) between the first-best equilibrium $(F B)$ and the fully decentralized equilibrium $(S B)$, as a function of $\sigma$ and $\rho$.

For combinations of $\rho$ sufficiently small and $\sigma$ sufficiently large, we could not establish decentralized equilibria that comply with segregation by income.

The figure suggests that the welfare loss from decentralization is highest for a combination of low rivalry and intermediate spillovers. For these parameter combinations, it is optimal to leave one municipality almost empty (for details, refer to Tables A3 and A4 in the Appendix). This is the result of two opposing forces: On the one hand, spillovers provide incentives for the poor to free-ride on the public good provision (and thus implicitly on the tax payments) of the rich municipality. On the other hand, imperfect rivalry implies economies of scale such that the poor households can profit from the rich municipality's payments by residing in the latter's municipality. As it turns out, the latter effect dominates for intermediate levels of spillovers. In contrast, the decentralized equilibrium is characterized by pronounced income segregation.

To obtain an ordinal measure of the welfare loss, we compute households' compensating variation $(\mathrm{CV})$, which we define as the income that a household needs to receive in the secondbest equilibrium to maintain its first-best utility level. $\left[{ }^{29}\right.$ Households with a positive $\mathrm{CV}$ are better off in the first-best equilibrium, whereas those with a negative $\mathrm{CV}$ are better off in the decentralized equilibrium. The aggregate monetized welfare loss of decentralization is the integral of the households' compensating variations $\left(C V^{a g g}\right)$. A quantification of the welfare loss from decentralization according to this measure is given by Figure A3 in the Appendix.

To gain more intuition about the costs of decentralization, we focus on the case of a 'semi-

\footnotetext{
${ }^{29}$ Formally, $C V(y)$ solves $V^{S B}\left(p_{j}^{S B}, t_{j}^{S B}, g_{j}^{S B} ;[y+C V(y)]\right)=V^{F B}\left(p_{j}^{F B}, T_{j}^{F B}, t_{j}^{F B}, g_{j}^{F B} ; y\right)$.
} 
Table 2: First-best vs. decentralized eqilibrium: The case of a 'semi-public' good.

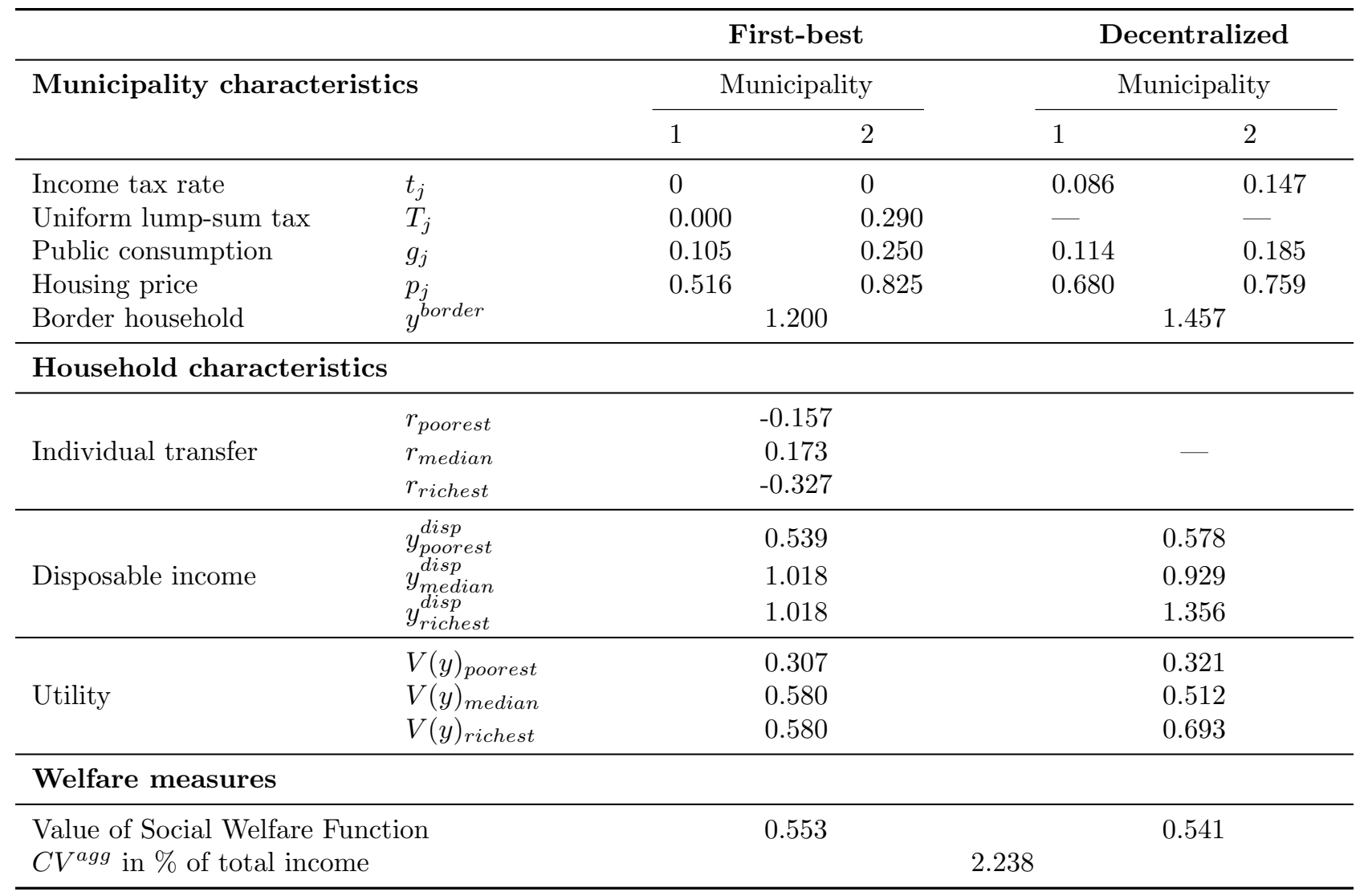

Results are for $\sigma=0.3$ and $\rho=0.5$. Households are uniformly distributed between $\underline{y}=1$ and $\bar{y}=2$. Integrals are approximated by modeling 101 household types with income $y=1,1.01,1.02, \ldots, 2$.

public' good characterized by $\sigma=\nu=0.3, \rho=0.5{ }^{30}$ The corresponding municipality and household characteristics of the first- and second-best equilibria are presented in Table $2{ }^{31}$

The decentralized equilibrium is associated with an aggregate monetized welfare loss equal to more than $2.2 \%$ of total income, substantially more than in the case of the publicly provided private good. In the decentralized solution, the border household is $y=1.457$, which means that the poorest $45.7 \%$ of the population self-select into municipality 1 , whereas the richer households choose to live in municipality 2. The social planner distributes households into an even more populated rich and an even less populated poor municipality.

Figure 4 shows individualized transfers, disposable income, utility levels and the CV as

\footnotetext{
${ }^{30}$ For the calibrated model of Kuhlmey (2017), which is an adjusted version of the current model, it is assumed that the "set of spillover-generating expenditure categories consist of health, culture and leisure, security, environment, and traffic". Using this categorization, the suburban municipalities in the metropolitan area around Zurich (Switzerland) spend around $25 \%$ of their budget on goods or services associated with a high degree of spillovers.

${ }^{31}$ The corresponding case of a publicly provided private good is shown in Table A2 and Figure A4 This has been the focus of the previous literature.
} 

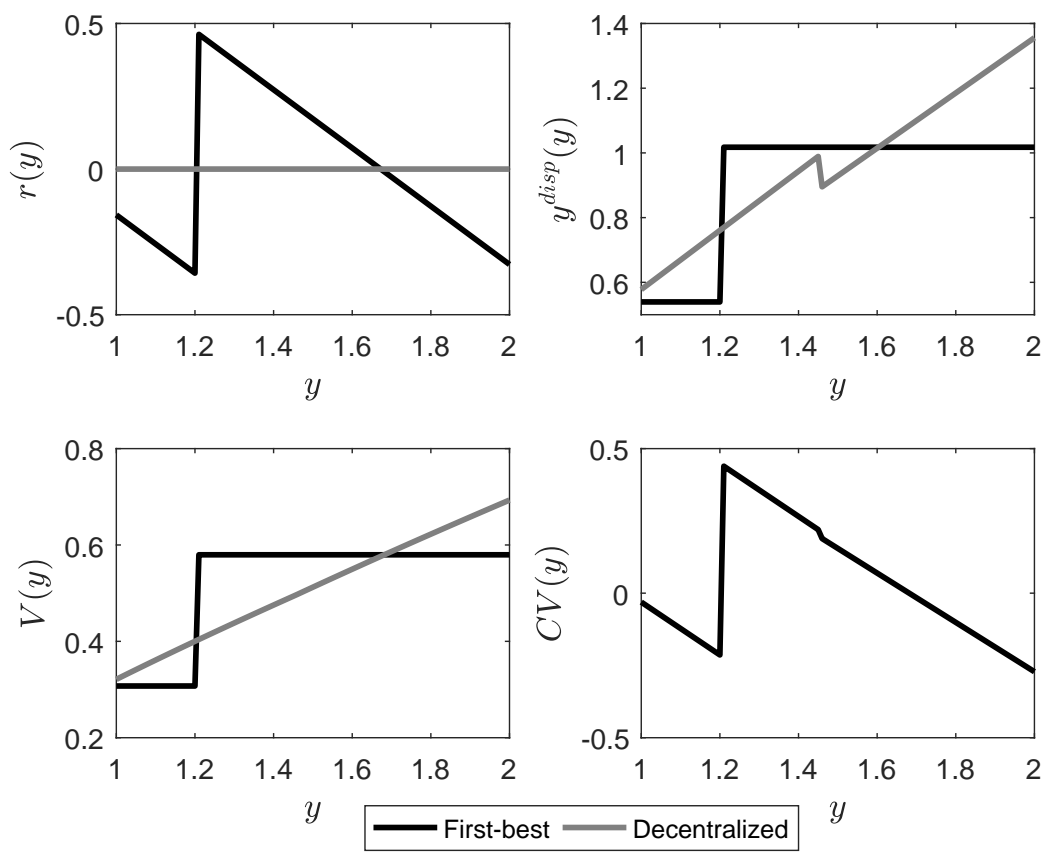

Figure 4: Household characteristic in FB and the fully decentralized equilibrium for the 'semipublic' good $(\sigma=0.3, \rho=0.5)$ : Individual transfer scheme $r(y)$, disposable income $y^{\text {disp }}(y)$, utility level $V(y)$, and compensating variation $C V(y)$.

a function of income. The planner imposes a municipality-specific linear transfer scheme, in which the inhabitants of the poor municipality, along with the richest households in the rich municipality, pay to subsidize the poorer inhabitants of the rich municipality (upper left panel).

Within each municipality, after taxes and transfers, everybody is equally well off (lower left panel). In contrast, the utility level in the decentralized equilibrium is monotonically increasing in $y$. Due to the lower housing price in the less crowded municipality, the poor households' utility is relatively close to their second-best values, whereas the poorer households in the rich municipality are substantially better off. Thus, the social planner improves the outcome for middle-income households at the expense of the poor and the rich. The corresponding CV mirrors this result. This result is due to the application of a utilitarian welfare function. In general, the social planner increases aggregate welfare relative to the decentralized solution by redistributing utility from some households to others. The exact pattern of this redistribution depends on the weights of the social welfare function. Calabrese et al. (2012) use implicit welfare weights that lead to zero redistribution. These welfare weights are regressive in that they are lower for the poor than they are for the rich households. Our finding that the rich households are better off in the competitive decentralized equilibrium in consistent with the results in Bucovetsky \& Glazer (2014). 


\subsection{Decomposition of the welfare loss}

The total welfare loss associated with decentralization is the combination of the following setup in the decentralized equilibrium: Imperfect tax instruments, a decentralized tax setting, and free mobility. To quantify the relative size of these different inefficiencies, we design different versions of the model, in which we impose increasingly tighter restrictions on the instruments available to the social planner. Among the several possibilities to do this, we choose a sequence that we believe is intuitive. Note further that the intermediate steps are conceptual in nature and do not describe a realistic policy scenario. We choose the same example of a "semi-public" good considered above, where $\sigma$ and $\rho$ are fixed at 0.3 and 0.5 , respectively. The resulting equilibria are described in Table 3.

Table 3: Decomposition of the welfare loss from decentralization.

\begin{tabular}{|c|c|c|c|c|c|c|c|c|c|}
\hline & & \multicolumn{2}{|c|}{ First-best } & \multicolumn{2}{|c|}{$\begin{array}{c}\mathbf{I} \\
r(y)=T=0\end{array}$} & \multicolumn{2}{|c|}{$\begin{array}{c}\text { II } \\
\text { (I) \& voting }\end{array}$} & \multicolumn{2}{|c|}{$\begin{array}{l}\text { Fully decent. } \\
\text { (II) \& mobility }\end{array}$} \\
\hline & & \multicolumn{2}{|c|}{ Municipality } & \multicolumn{2}{|c|}{ Municipality } & \multicolumn{2}{|c|}{ Municipality } & \multicolumn{2}{|c|}{ Municipality } \\
\hline & & 1 & 2 & 1 & 2 & 1 & 2 & 1 & 2 \\
\hline Income tax rate & $t_{j}$ & 0 & 0 & 0.000 & 0.175 & 0.006 & 0.156 & 0.086 & 0.147 \\
\hline Uniform lump-sum tax & $T_{j}$ & 0.000 & 0.290 & - & - & - & - & - & - \\
\hline Public consumption & $g_{j}$ & 0.105 & 0.250 & 0.105 & 0.244 & 0.081 & 0.206 & 0.114 & 0.185 \\
\hline Housing price & & 0.516 & 0.825 & 0.526 & 0.824 & 0.597 & 0.801 & 0.680 & 0.749 \\
\hline Border household & $y^{\text {border }}$ & \multicolumn{2}{|c|}{1.200} & \multicolumn{2}{|c|}{1.180} & \multicolumn{2}{|c|}{1.280} & \multicolumn{2}{|c|}{1.457} \\
\hline \multirow{2}{*}{\multicolumn{2}{|c|}{$\begin{array}{l}\text { Value of SWF } \\
C V^{\text {agg }} \text { (in } \% \text { of total income) }\end{array}$}} & \multicolumn{2}{|c|}{0.5526} & \multicolumn{2}{|c|}{0.5498} & \multicolumn{2}{|c|}{0.5456} & \multirow{2}{*}{\multicolumn{2}{|c|}{0.5405}} \\
\hline & & & & & & & & & \\
\hline \multicolumn{2}{|c|}{ Relative size of welfare loss } & & \multicolumn{2}{|c|}{$\begin{array}{c}37.7 \% \\
\text { Imperfect } \\
\text { redistribution }\end{array}$} & \multicolumn{2}{|c|}{$\begin{array}{c}30.5 \% \\
\text { Inter-municipal } \\
\text { free-riding }\end{array}$} & $\begin{array}{l}\text { Jur } \\
\text { choice }\end{array}$ & $\begin{array}{l}8 \% \\
\text { ctional } \\
\text { ternality }\end{array}$ & \\
\hline
\end{tabular}

Results are for $\sigma=0.3$ and $\rho=0.5$. Households are uniformly distributed between $y=1$ and $\bar{y}=2$. Integrals are approximated by modeling 101 household types with income $y=1,1.01,1.02, \ldots, 2$.

In step I, we set $r(y)=0$ and $T_{j}=0$, thus restricting the social planner's ability to redistribute to linear income taxation. Since households living in the same municipality consume the same amount of the public good but pay different taxes, redistribution takes place in the form of public provision financed predominantly by the rich. The level of public provision (and thus the income tax rates), and also the distribution of households across municipalities remains determined by the social planner ${ }^{32}$ The welfare loss resulting from eliminating inter-

\footnotetext{
${ }^{32}$ In principle, one could separate this step into one step where lump-sum taxes are ruled out but head taxes are still allowed, and a second step where head taxes are removed from the set of available policy instrument.
} 
municipal redistribution amounts to $2.238-1.394=0.84 \%$ of total income, which is roughly a third of the total welfare loss from decentralization for the given parameters.

In step II, the municipalities are allowed to choose their own income tax rates and thus their level of public provision by majority vote, such that the role of the social planner is reduced to allocating the population across municipalities. This step introduces inter-municipal freeriding: Because some of the local public production is consumed in the other municipality, the utility-maximizing median voter does not consider the full benefits associated with his choice of local income taxes, and will thus choose a tax rate that is below the social optimum. At the same time, he or she free-rides on the public provision from outside the municipality borders. The levels of public consumption significantly drop in both municipalities. The inefficiency due to inter-municipal free-riding accounts for roughly another third of the total overall welfare loss.

Also included in moving from step I to step II is the inefficiency that results from voting per se. In an attempt to isolate the voting inefficiency, we have introduced local social planners in both municipalities. These take the household distribution and the majority-voting outcome in the other municipality as given by version II, but choose the socially optimal level of the tax rate, accounting for the municipality-specific dynamics (such as the adjustment of the housing prices). Due to the concavity of the utility function, the planners place a larger weight on poorer households than the median voter, which leads to a marginally higher tax rate (which is the sole means of redistribution at this stage of the model). The resulting difference in the compensating variation relative to the fully decentralized equilibrium with majority voting is marginal, implying that the voting inefficiency is not a major source of welfare loss in our setup (Table A5 in the Appendix gives the details)

Finally, letting households self-select into municipalities leads to the fully decentralized solution discussed above. This last step captures the JCE, conditional on the equilibrium at step II: When selecting their preferred municipality, households do not consider the fiscal burden they impose on other municipality members via income tax payments, public consumption, and

However, given that income is fixed in our model, income taxation does not entail a deadweight loss in terms of factor supply and is thus not qualitatively different to a specific combination of a lump-sum tax with a linear income tax. For this reason, we chose to combine the removal of $r(y)$ and $T_{j}$ into a single 'redistribution' step.

${ }^{33}$ Alternatively, one could try to isolate the inefficiency from voting by comparing the first-best situation, where all decisions are made by a social planner, with a model where the decisions are made by a central median voter. However, this is complicated by the presence of spillovers and congestion. A uniform public consumption, which could serve as a benchmark for the decentralized outcome, is only consistent with zero or perfect spillovers. If spillovers are imperfect, the location of the central median voter would matter. 


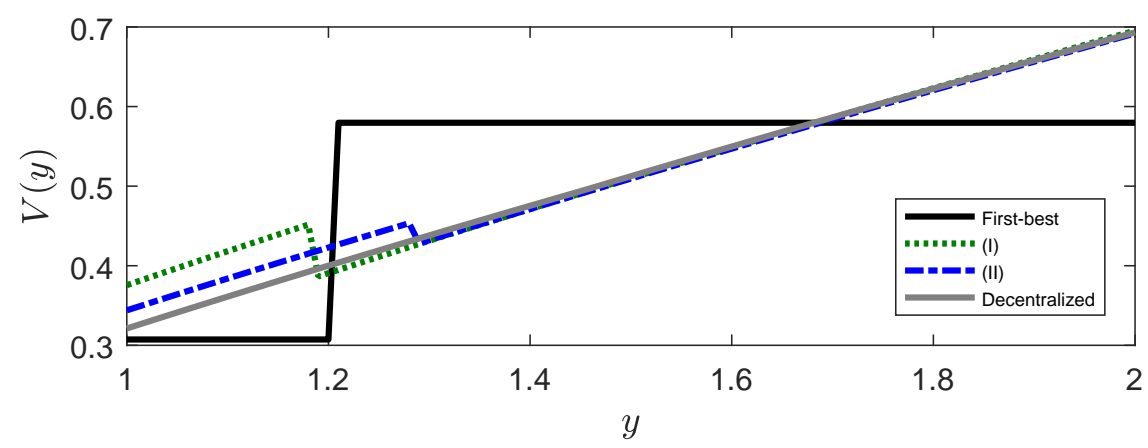

Figure 5: Utility as a function of income $(\sigma=0.3, \rho=0.5)$.

the housing market. The result is an inefficient population distribution, which is responsible for the remaining third of the overall welfare loss in our baseline case.

Figure 5 displays the household-specific utility levels and thus identifies the winners and losers of each decentralization step. The utility levels in the first-best (black) and the decentralized (gray) equilibria correspond to those in the bottom left graph of Figure 4 and show that decentralization implies an increase in utility for the rich and the poor, at the expense of households in the middle-income range. The utility levels of these households (those with income between 1.2 and 1.7) are close to their second-best utility level at decentralization step I. Inefficient public provision due to inter-municipal free-riding (I to II) mainly hurts the poor, for whom public consumption constitutes a larger share of total consumption. In the last step, the JCE reduces the utility of the poorest third of the population, while making the remainder of the population marginally better off.

We now investigate to what extent these results depend on the level of spillovers and congestion. Figure 6 shows the welfare loss at different decentralization steps for $\rho=0.5$, computed for the range of different values for $\sigma$, in terms of the welfare function (top panel) and the aggregate CV relative to the fully decentralized equilibrium (bottom panel). Social welfare is increasing in $\sigma$ for all equilibria that are not fully decentralized, due to the larger benefits associated with producing a unit of the public good. The inefficiencies associated with imperfect redistribution, spillovers and the locational choice of households turn out to neutralize this mechanical welfare increase almost completely, such that the SWF of the fully decentralized equilibrium is relatively insensitive to the value of $\sigma$.

The welfare loss from restricting the available policy instruments to nonbenefit taxation is represented by the difference between the solid and dotted lines. This inefficiency decreases 

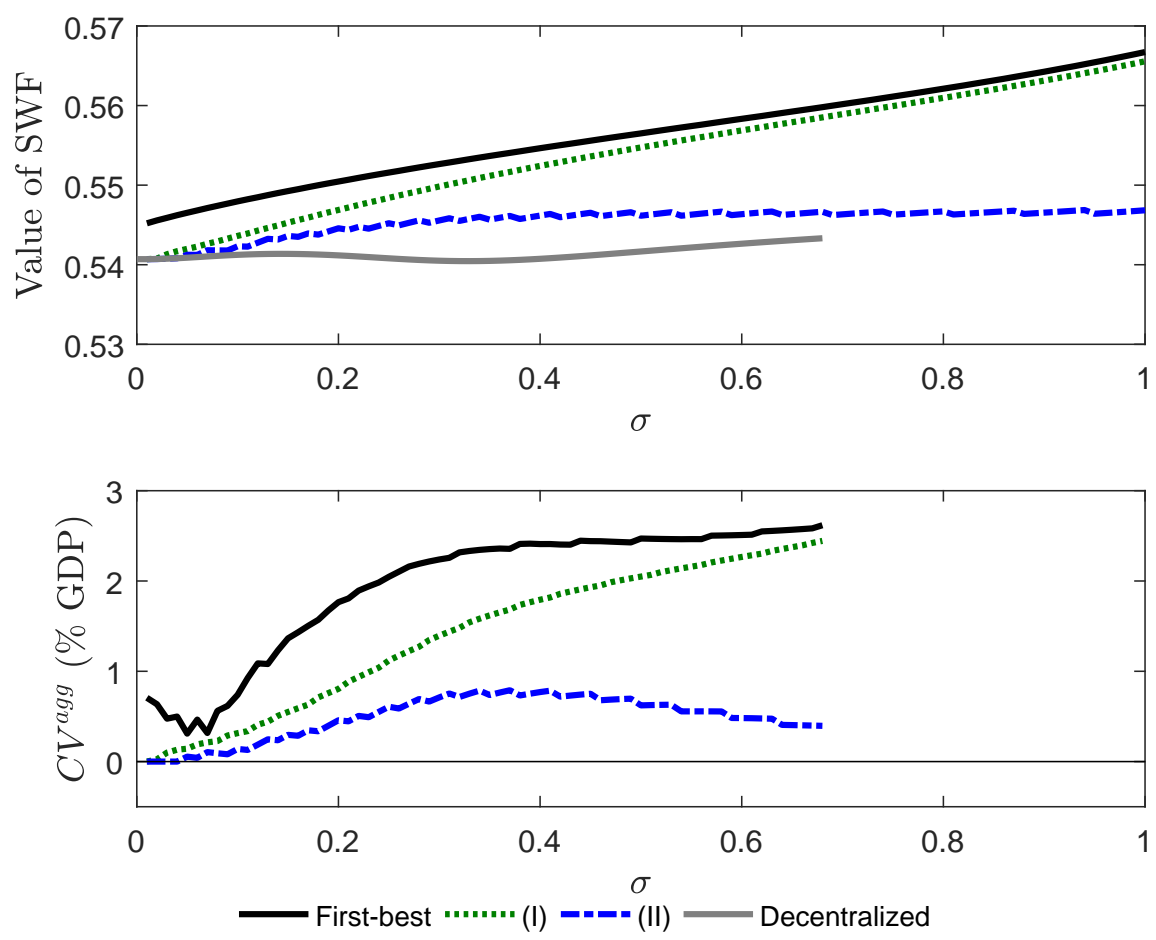

Figure 6: Decomposition of the welfare loss for varying $\sigma(\rho=0.5)$ : Value of the social welfare function $(\mathrm{SWF})$ and aggregate compensating variation $\left(C V^{a g g}\right)$ in $\%$ of total income.

with the strength of spillovers. ${ }^{34}$ As municipal boundaries become more porous, the income spent on public production increasingly reaches the population in other municipalities, thus providing an alternative pathway for redistribution. In our model, it is the rich municipality that produces more of the public good, such that spillovers effectively redistribute from rich to poor, as would be the case with individualized head taxes. This result is qualitatively similar to the model by Wellisch (1994) in the sense that spillovers can serve a substitute for monetary payments and thus reduce regional welfare differentials.

The welfare loss due to inter-municipal free-riding is captured by the difference between decentralization steps I and II. The median voter in each municipality has no incentive to consider the benefit of local public production that accrues elsewhere. As spillovers increase, this inefficiency naturally becomes more important.

\footnotetext{
${ }^{34}$ The relative welfare losses due to the inter-municipal free-riding and the JCE are qualitatively similar when measured with the SWF or the CV. However, not having access to individualized transfers (the difference between first-best and step I in Figure 6) has a much larger welfare effect in terms of the CV than in terms of the value of the SWF. The underlying reason is that the CV for a given change in utility depends on a household's income level. The non-monotonicity of the solid line in the bottom panel in Figure 6 is due to different households being expropriated by the social planner, due to very different population distributions at low levels of $\sigma$
} 

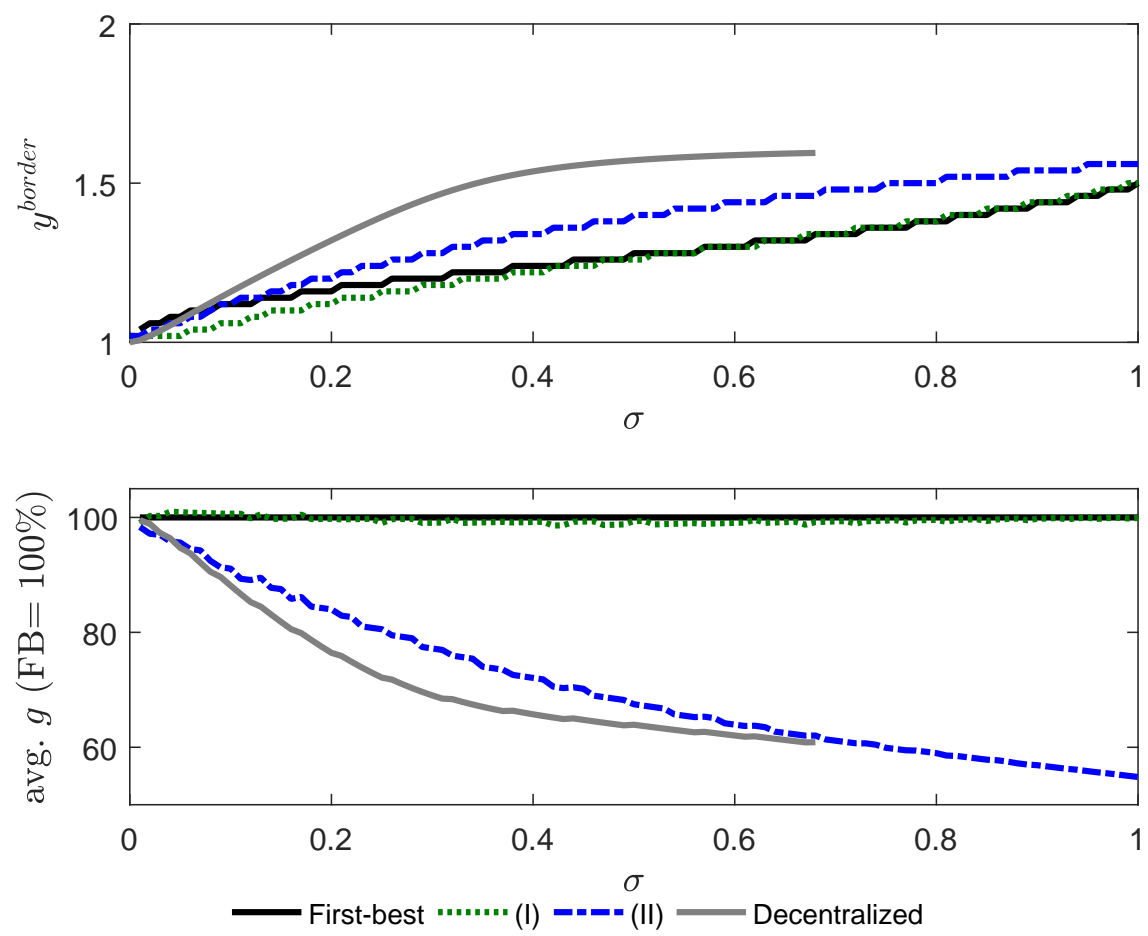

Figure 7: Decomposition of the welfare loss for varying $\sigma(\rho=0.5)$ : Border household $y^{\text {border }}$ and population-weighted public consumption $g \equiv \sum_{j} N_{j} g_{j}$., relative to first-best levels.

The welfare loss from the JCE is non-monotonic in $\sigma 35$ It is the difference between the lines associated with step II and the fully decentralized equilibrium in the top panel, and its monetized version is given by line (II) in the bottom panel. The underlying reason is the population distribution, which is shown in the top panel of Figure 7. Without spillovers, the entire population resides in municipality 2 in all steps of decentralization, due to the considerable economies of scale reflected by $\rho=0.5$ that underlies this figure. As spillovers increase, municipality 1 is gradually populated, but at different rates across the different decentralization steps. In particular, households leave municipality 2 at a "faster" pace in the fully decentralized equilibrium, relative to step II, which leads to an increase in the welfare loss due to the $\mathrm{JCE} \cdot{ }^{36}$ However, unlike the "poor chase rich" result identified in the previous literature, it is the poor community that is inefficiently crowded. The inefficiency from this "poor flee rich" effect stems from the fact that the households that move to municipality 1 free-ride on the public production in municipality 2 (and enjoy low housing prices), without contributing much

\footnotetext{
${ }^{35}$ We stress that this is the welfare loss from the JCE (which is one number and positive by construction), not the JCE itself (which depends on the municipality and the income level of the involved household, and which can be positive or negative).

${ }^{36}$ Recall that these are equilibrium outcomes, such that by "faster" we mean a higher correlation between $\sigma$ and the income of the equilibrium border household at low levels of spillovers.
} 
to the public good themselves, even though a larger public production in municipality 2 would be preferable from a social point of view. As a result, the average public consumption deceases (bottom panel of Figure 7), and the welfare loss from the JCE increases.

Once spillovers become sufficiently strong, the population distribution and the average public consumption level become increasingly similar in step II and the decentralized equilibrium (and the same is true for tax rates and housing prices). This reduces the dependency of households' utility on the locational choice, and thus the inefficiency that can arise from a decentralized allocation of the population. As a consequence, the welfare loss from the JCE declines with $\sigma$. This effect at high levels of spillovers is qualitatively similar to findings from tax competition models, where spillovers mitigate the inefficiency from not considering the benefits of the outflow of the tax base that accrues in other regions as some of this tax base "spills back" (Bloch \& Zenginobuz 2015, Armbruster \& Hintermann 2019).

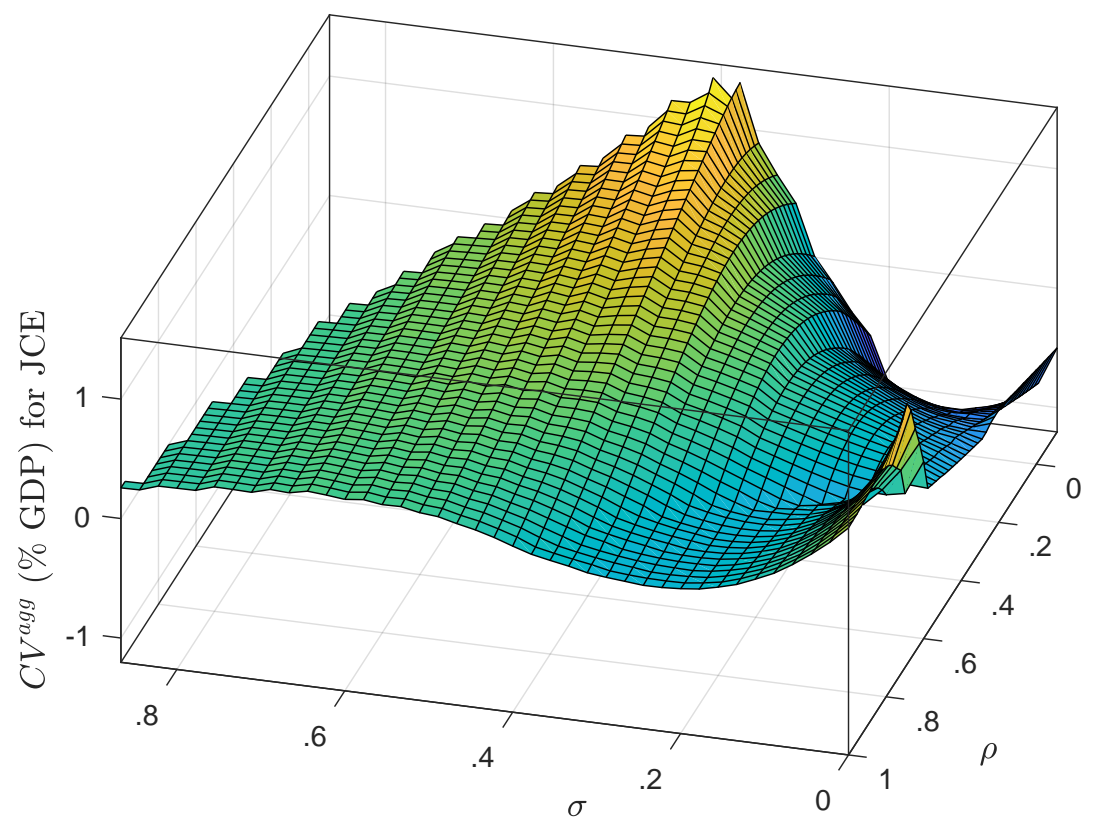

Figure 8: Jurisdictional choice externality as a function of spillovers and congestion

The relationship between spillovers and the the welfare loss from the JCE depends on the level of the assumed congestion, especially at low levels of $\sigma$. Figure 8 shows the JCE in terms of the aggregated compensating variation relative to the decentralized equilibrium for all combinations of $\sigma$ and $\rho$. The figure suggests that the case of $\rho=0.5$ (the blue dashed line in the bottom panel of Figure 6) is somewhat special, as for lower and higher levels of congestion, the welfare loss is first decreasing in $\sigma$, before increasing and finally decreasing at sufficiently 


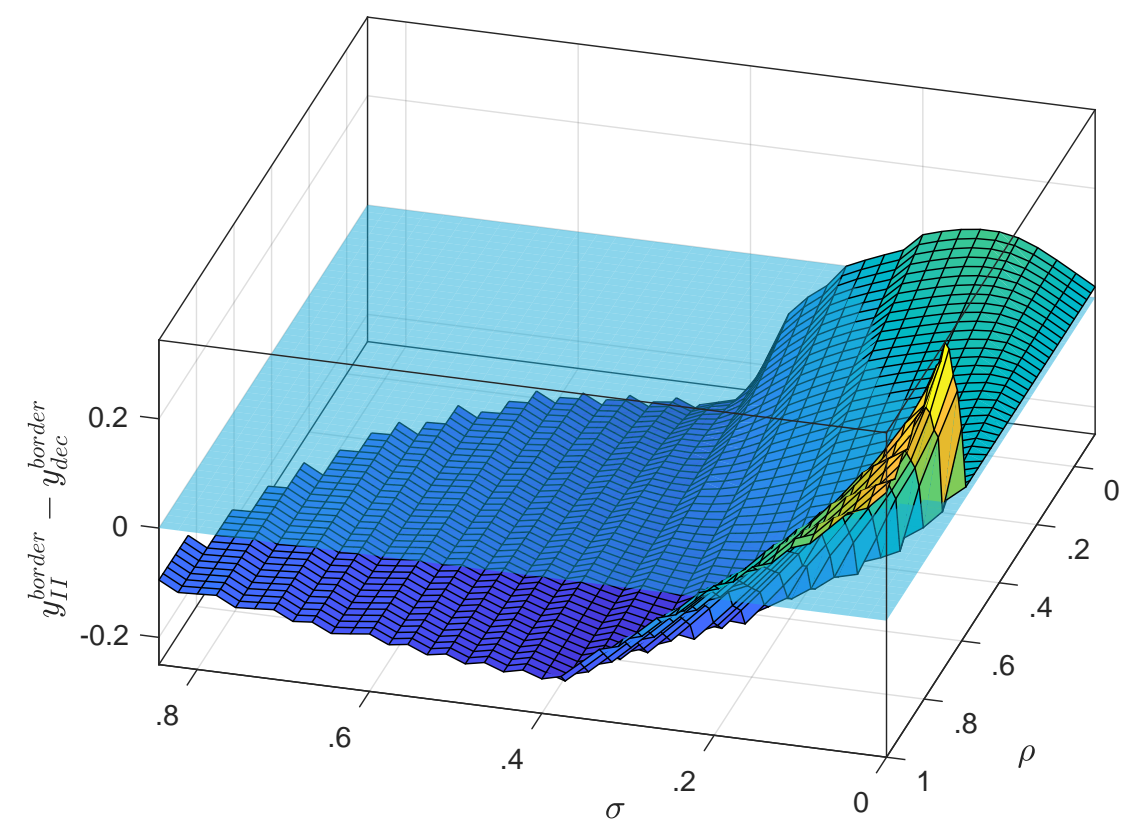

Figure 9: Difference in incomes of border household in step II and the decentralized equilibrium.

Positive values imply relative crowding of the rich municipality ("poor chase rich"), whereas negative values mean that fewer households live in the rich municipality than what would be socially optimal ("poor flee rich").

high levels of spillovers.

The key to understanding this additional non-monotonicity at low levels of $\sigma$ is once again the population distribution. Figure 9 shows the difference between the income of the border household in step II and the decentralized equilibrium for all values of $\sigma$ and $\rho$. A positive difference implies that the share of the population living in the rich municipality is larger in the decentralized equilibrium than in step II (where the population is assigned by the social planner). This corresponds to "poor chase rich", where poor households move into the rich municipality in order to benefit from the tax payments of high-income households. This is the case for $\sigma / \rho$ combinations close to the publicly provided private good, and also for combinations of low $\sigma /$ low $\rho$ (but not for $\rho=0.5$, and thus it cannot be seen in Figures 667).

Consider the case of a publicly provided private good $(\sigma=0, \rho=1)$, which is associated with a strong over-crowding of the rich community. Introducing positive levels of spillovers mitigates the "poor chase rich" effect, because public consumption increases in the poor community, and as a consequence, the poor households' incentive to crowd into the rich municipality is reduced. As spillovers increase, the population distribution in the decentralized equilibrium reaches a point where it is exactly efficient (the intersection between the curved surface and the zero-surface in Fig. 9), such that the welfare loss from the JCE is zero. This explains the 
initial decease of the welfare loss as a function of $\sigma$ in Figure 8 , for low and high levels of $\rho$.

If spillovers increase further, the population distribution switches to "poor flee rich" discussed in the context of Figures 647. For high levels of $\sigma$, the poor community is sufficiently attractive to drive housing prices to above those in the rich municipality (Figure 2). If spillovers increase even more, the characteristics of the municipalities converge and the welfare loss of the JCE decreases, as discussed above.

\subsection{Sensitivity analysis}

In this subsection, we assess the sensitivity of our results with respect to the following key parameters: The elasticity of the housing supply, the preference parameters for housing and the publicly provided good, and the subsistence levels for the numeraire good and for housing. Starting with the baseline results from Table 3, we apply variations in one parameter while holding the others fixed. Table 4 shows a summary of the resulting welfare loss in terms of the compensating variation (CV) and its distribution across the decentralization steps. Equilibrium values of the border household, aggregate community income, housing prices, tax rates and public production at each step are provided in Table A6 in the Appendix.

Table 4: Sensitivity analysis: Decomposition of the welfare loss in terms of the aggregated compensating variation (in \% of GDP), for $\sigma=0.3$ and $\rho=0.5$.

\begin{tabular}{|c|c|c|c|c|c|}
\hline & & \multirow{2}{*}{$\begin{array}{l}C V^{a g g} \\
(\% \text { of } G D P)\end{array}$} & \multicolumn{3}{|c|}{ Decomposition of the welfare loss (in \%) } \\
\hline & & & Redistribution & Free-riding & JCE \\
\hline Baseline & See Table 1 . & 2.26 & 38.3 & 30.2 & 31.5 \\
\hline Price-elasticity of HS & $\begin{array}{l}\theta=1.5 \\
\theta=3.5\end{array}$ & $\begin{array}{l}1.80 \\
1.80\end{array}$ & $\begin{array}{l}49.2 \\
32.6\end{array}$ & $\begin{array}{l}30.2 \\
35.1\end{array}$ & $\begin{array}{l}20.5 \\
32.2\end{array}$ \\
\hline Public good preference & $\begin{array}{l}\alpha \text { low } \\
\alpha \text { high }\end{array}$ & $\begin{array}{l}1.65 \\
2.85\end{array}$ & $\begin{array}{l}39.9 \\
38.3\end{array}$ & $\begin{array}{l}29.3 \\
31.4\end{array}$ & $\begin{array}{l}30.7 \\
30.4\end{array}$ \\
\hline Housing preference & $\begin{array}{l}\gamma \text { low } \\
\gamma \text { high }\end{array}$ & $\begin{array}{l}2.33 \\
2.18\end{array}$ & $\begin{array}{l}38.4 \\
38.3\end{array}$ & $\begin{array}{l}30.7 \\
30.1\end{array}$ & $\begin{array}{l}30.8 \\
31.6\end{array}$ \\
\hline Subsistence level for $x$ & $\begin{array}{l}\beta_{x} \text { low } \\
\beta_{x} \text { high }\end{array}$ & $\begin{array}{l}2.29 \\
2.21\end{array}$ & $\begin{array}{l}37.5 \\
39.0\end{array}$ & $\begin{array}{l}29.9 \\
28.5\end{array}$ & $\begin{array}{l}32.5 \\
32.5\end{array}$ \\
\hline Subsistence level for $h$ & $\begin{array}{l}\beta_{h} \text { low } \\
\beta_{h} \text { high }\end{array}$ & $\begin{array}{l}2.40 \\
2.12\end{array}$ & $\begin{array}{l}33.4 \\
43.9\end{array}$ & $\begin{array}{l}34.7 \\
26.5\end{array}$ & $\begin{array}{l}32.0 \\
29.6\end{array}$ \\
\hline
\end{tabular}

The labels "high" and "low" refer to parameter values that are $20 \%$ above and $20 \%$ below the respective baseline values.

The results change in an intuitive way for all parameter perturbations. For example, an 
increase in the preference for housing $(\gamma)$ implies an increase in housing prices. Higher subsistence levels for $x$ and $h$ lead to a decrease in disposable income, which in turn results in a lower welfare loss from decentralization, because there is less scope for a strategic substitution between private and public consumption. At the same time, the relative contribution of imperfect redistribution is somewhat larger because households are more income-constrained. The welfare loss from free-riding is more pronounced if we assume a higher level of the preference parameter for the publicly provided good $(\alpha)$, and it is less relevant for lower levels of $\alpha$.

The comparison of the border household in step II with that in the fully decentralized equilibrium reveals that the "poor flee rich" result from our baseline is robust to all parameter variations with the exception of an increase in the price elasticity of the housing supply. With $\theta=3.5$ (instead of 3), housing becomes cheaper, such that it becomes attractive for the poor to completely 'chase' the rich, thereby leaving the poor municipality empty (recall that these model runs are based on $\rho=0.5$, which implies significant economies of scale in the production of the public good). For this model run, the relative welfare loss from the JCE is slightly higher (32.2\% instead of $31.5 \%)$, but the absolute welfare loss is smaller ( $0.58 \%$ of GDP vs. $0.71 \%$ ), which is due to the lower cost of housing.

Table A6 also reports equilibrium values for changes of the welfare function (SWF): Instead of equal welfare weights as applied by a utilitarian social planner, we apply welfare weights that are increasing or decreasing in income. We have assumed rather strong changes, with the welfare weights either increasing from 1 to 101 or decreasing from 101 to 1 . In both cases, the aggregate welfare loss from decentralization is larger, with $6 \%$ and $13.5 \%$ for increasing and decreasing weights, respectively. Intuitively, the part of the population with the lower welfare weights is kept near its subsistence level by the social planner, whereas the share of the population with the highest welfare weights is much better off in first-best relative to the decentralized case (where no SWF is applied). The CV for decreasing welfare weights is more than twice as high than the CV for increasing weights. The reason is that in the former case, it is the rich who require compensation (which translates to a large monetary compensation due to their low marginal utility of income), whereas the latter case the poor are compensated ${ }^{37}$

\footnotetext{
${ }^{37}$ The different tradeoff between utility and money for households of different income levels is the reason why the aggregate compensating variation turns negative for decentralization steps I and II. The respective level of the SWF, which is the relevant measure from the perspective of the social planner, is higher at each step of decentralization than in the fully decentralized equilibrium.
} 


\section{Conclusions}

We extend a model of tax-induced Tiebout sorting by allowing for interjurisdictional spillovers and imperfect congestion of the publicly provided good. The presence of spillovers or imperfect rivalry in consumption introduces additional terms to the equilibrium conditions, which render the utility of households in all municipalities a function of the public production in all other municipalities. We derive a modified Samuelson rule for decentralized public production in the presence of spillovers and imperfect congestion, and also highlight the inefficiency arising from households' decentralized choice of residence. This jurisdictional choice externality is the consequence of households not considering their fiscal impact on others, both in their residence of choice (via congestion) and in other municipalities (via spillovers).

We implement our model numerically for all meaningful values for spillovers and congestion. We find that an increase in spillovers leads to a reduction in the difference between the municipalities with respect to income levels, tax rates, and the consumption levels of the publicly provided good. If spillovers are sufficiently large, income tax competition breaks down in the sense that households no longer segregate by income.

We separate the welfare cost of moving from a unified model, in which a social planner makes all decisions, to a fully decentralized equilibrium where households are mobile and where the median voter decides on the level of tax rates (and thus public production), into three categories: (1) imperfect redistribution, (2) inter-municipal free-riding and (3) the jurisdictional choice externality. We find that the attributes of the publicly provided private good affect the composition of the welfare loss in important ways. The higher the level of spillovers, the higher the inefficiency due to free-riding, which is intuitive, and the lower is the inefficiency due to constrained redistribution. This implies that spillovers constitute an alternative pathway for redistribution, which is qualitatively similar to results derived using models in the context of head taxes (e.g., Wellisch 1993).

Perhaps most interestingly, spillovers affect the inefficiency due to the JCE in a nonmonotonic way. If spillovers increase from zero, the result of the decentralized locational choice switches from crowding of the rich community to crowding of the poor community, before becoming close to efficient at high levels of spillovers. This translates to a welfare loss that is first decreasing, then increasing, and then again decreasing in $\sigma$. The "poor flee rich" 
effect that we identify is new to the literature, and due to the fact that spillovers allow poor households to free-ride on the public production in the rich municipality while enjoying low tax rates and housing prices. Allowing for a more general definition of the public good thus leads to qualitatively different implications of decentralization in terms of household sorting.

Our results for large levels of spillovers are similar in spirit to findings in capital tax competition models, where spillovers reduce the inefficiency of tax competition, because a part of the capital that flows to other region "spills back" (Ogawa \& Wildasin 2009, Eichner \& Runkel 2012). The technical inefficiency thus mitigates the fiscal inefficiency from the decentralized setting of tax rates in the presence of a mobile tax base.

Although our stylized model does not allow us to derive specific policy implications, our results suggest that in the presence of exogenous jurisdictional borders, there is no simple allocation rule to determine what kinds of goods and services should be provided at the different levels of government, but that this crucially depends on their degree of rivalry in consumption and the strength of interjurisdictional spillovers.

It would be interesting to extend our analysis to more realistic distributions of income, to progressive taxation, to jurisdictions of different sizes, or to allow for spillovers to be asymmetric between municipalities. Also, in order to bring the model closer to reality, it would make sense to add a vertical dimension of the federal system by introducing a central authority with access to some redistributive grants or another means of fiscal equalization.

\section{References}

Armbruster, S. \& Hintermann, B. (2019), 'Decentralization with porous borders: Public production in a federation with tax competition and spillovers', WWZ Working Papers 2019(03).

Bjorvatn, K. \& Schjelderup, G. (2002), 'Tax competition and international public goods.', International Tax and Public Finance 9(2), 111 - 120.

Bloch, F. \& Zenginobuz, E. (2006), 'Tiebout equilibria in local public good economies with spillovers', Journal of Public Economics 90(8), 1745-1763.

Bloch, F. \& Zenginobuz, Ü. (2015), 'Oates' decentralization theorem with imperfect household mobility', International Tax and Public Finance 22(3), 353-375.

Boadway, R. \& Tremblay, J.-F. (2012), 'Reassessment of the Tiebout model.', Journal of Public Economics 96(11-12), 1063 - 1078. 
Bruelhart, M., Bucovetsky, S. \& Schmidheiny, K. (2015), Taxes in cities, in J. V. H. Gilles Duranton \& W. C. Strange, eds, 'Handbook of Regional and Urban Economics', Vol. 5, Elsevier, pp. $1123-1196$.

Bucovetsky, S. (2011), 'Incentive equivalence with fixed migration costs.', Journal of Public Economics 95(11-12), 1292 - 1301.

Bucovetsky, S. \& Glazer, A. (2014), 'Efficiency, equilibrium and exclusion when the poor chase the rich', Journal of Urban Economics 81, 166-177.

Calabrese, S. M., Epple, D. N. \& Romano, R. E. (2012), 'Inefficiencies from metropolitan political and fiscal decentralization: Failures of Tiebout competition', The Review of Economic Studies 79(3), 1081 - 1111.

Caplan, A. J., Cornes, R. C. \& Silva, E. C. D. (2000), 'Pure public goods and income redistribution in a federation with decentralized leadership and imperfect labor mobility.', Journal of Public Economics 77(2), 265 - 284.

Caplan, A. J. \& Silva, E. C. D. (2011), 'Impure public goods, matching grant rates and income redistribution in a federation with decentralized leadership and imperfect labor mobility.', International Tax and Public Finance 18(3), 322 - 336.

Eichner, T. \& Runkel, M. (2012), 'Interjurisdictional spillovers, decentralized policymaking, and the elasticity of capital supply.', American Economic Review 102(5), 2349 - 2357.

Epple, D. \& Nechyba, T. (2004), Fiscal decentralization, in J. V. Henderson \& J. F. Thisse, eds, 'Handbook of Regional and Urban Economics', Vol. 4, Elsevier, pp. 2423-2480.

Epple, D. \& Platt, G. (1998), 'Equilibrium and local redistribution in an urban economy when households differ in both preferences and incomes', Journal of Urban Economics 43(1), 2351.

Epple, D. \& Romer, T. (1991), 'Mobility and redistribution', Journal of Political Economy 99(4), $828-858$.

Epple, D., Romer, T. \& Sieg, H. (2001), 'Interjurisdictional sorting and majority rule: An empirical analysis', Econometrica 69(6), 1437-1465.

Epple, D. \& Zelenitz, A. (1981), 'The roles of jurisdictional competition and of collective choice institutions in the market for local public goods.', American Economic Review 71(2), 87 92.

Feld, L. P. \& Kirchgaessner, G. (2001), 'Income tax competition at the state and local level in Switzerland', Regional Science and Urban Economics 31(2-3), 181-213.

Gravel, N. \& Oddou, R. (2014), 'The segregative properties of endogenous jurisdiction formation with a land market', Journal of Public Economics 117, 15 - 27.

Gravel, N. \& Thoron, S. (2007), 'Does endogenous formation of jurisdictions lead to wealthstratification?', Journal of Economic Theory 132(1), 569-583.

Hansen, N. A. \& Kessler, A. S. (2001a), '(Non-) existence of equilibria in multicommunity models', Journal of Urban Economics 50(3), 418-435.

Hansen, N. A. \& Kessler, A. S. (2001b), 'The political geography of tax h(e)avens and tax hells', American Economic Review 91(4), 1103-1115. 
Henchman, J. \& Sapia, J. (2011), Local income taxes: City- and county-level income and wage taxes continue to wane, Tax Foundation.

Hoel, M. (2004), 'Interregional interactions and population mobility.', Journal of Economic Behavior and Organization 55(3), 419 - 433.

Hoel, M. \& Shapiro, P. (2003), 'Population mobility and transboundary environmental problems', Journal of Public Economics 87(5-6), 1013 - 1024.

Hoel, M. \& Shapiro, P. (2004), 'Transboundary environmental problems with mobile but heterogeneous populations.', Environmental and Resource Economics 27(3), 265 - 271.

Kaplow, L. (2006), 'Public goods and the distribution of income', European Economic Review 50(7), 1627-1660.

Kuhlmey, F. (2017), 'Local income tax competition with progressive taxes and a fiscal equalization scheme', WWZ Working Papers 2017(17).

Loeper, A. (2017), 'Cross-border externalities and cooperation among representative democracies', European Economic Review 91, 180-208.

Mansoorian, A. \& Myers, G. M. (1993), 'Attachment to home and efficient purchases of population in a fiscal externality economy.', Journal of Public Economics 52(1), 117 - 132.

Myers, G. M. (1990), 'Optimality, free mobility, and the regional authority in a federation.', Journal of Public Economics 43(1), 107 - 121.

Nechyba, T. J. (1997), 'Existence of equilibrium and stratification in local and hierarchical tiebout economies with property taxes and voting', Economic theory 10(2), 277-304.

Oates, W. E. (1972), Fiscal Federalism, Harcourt Brace Jovanovich, New York.

Oates, W. E. (1999), 'An essay on fiscal federalism.', Journal of Economic Literature $\mathbf{3 7}(3), 1120-1149$.

Oddou, R. (2016), 'The effect of spillovers and congestion on the endogenous formation of jurisdictions', Journal of Public Economic Theory 18(1), 67-83.

Ogawa, H. (2006), 'Tax competition, spillovers, and subsidies', The Annals of Regional Science 40(4), 849-858.

Ogawa, H. \& Wildasin, D. E. (2009), 'Think locally, act locally: Spillovers, spillbacks, and efficient decentralized policymaking.', American Economic Review 99(4), 1206 - 1217.

Ross, S. \& Yinger, J. (1999), 'Sorting and voting: A review of the literature on urban public finance', Handbook of Regional and Urban Economics 3, 2001-2060.

Sato, M. (2003), 'Tax competition, rent-seeking and fiscal decentralization', European Economic Review 47(1), 19-40.

Schmidheiny, K. (2002), Community Choice and Local Income Taxation, PhD thesis, University of Berne.

Schmidheiny, K. (2006a), 'Income segregation and local progressive taxation: Empirical evidence from Switzerland', Journal of Public Economics 90(3), 429-458. 
Schmidheiny, K. (2006b), 'Income segregation from local income taxation when households differ in both preferences and incomes.', Regional Science and Urban Economics 36(2), 270 -299 .

Silva, E. C. D. \& Caplan, A. J. (1997), 'Transboundary pollution control in federal systems.', Journal of Environmental Economics and Management 34(2), 173 - 186.

Tiebout, C. M. (1956), 'A pure theory of local expenditures.', Journal of Political Economy 64, $416-424$.

Wellisch, D. (1993), 'On the decentralized provision of public goods with spillovers in the presence of household mobility.', Regional Science and Urban Economics 23(5), 667 - 679.

Wellisch, D. (1994), 'Interregional spillovers in the presence of perfect and imperfect household mobility.', Journal of Public Economics 55(2), 167 - 184.

Wilson, J. D. (1999), 'Theories of tax competition', National Tax Journal 52, 269-304.

Wilson, J. D. \& Wildasin, D. E. (2004), 'Capital tax competition: Bane or boon.', Journal of Public Economics 88(6), 1065 - 1091. 


\section{Appendix}

\section{A1. Proof that $\eta=0$ in first-best}

This proof is an adjusted version of Proposition 3 in Calabrese et al. (2012). In the first-best environment where the social planner has access to individualized transfers, $\eta_{j}=0$ for any combination of welfare weights. To show this, note that for income-segregated equilibria (on which we concentrate), the summation terms in (14) can be dropped because $a_{i}=0$ for all municipalities other than municipality $j$, which contains the income level $y$ :

$$
\omega(y) V_{y}^{j}(y)+\eta_{j} h_{y}^{j}(y)=\omega_{R}
$$

Multiplying both sides by $h^{j}(y) a_{j}(y)$, integrating over the support of the income distribution and substituting housing market clearance leads to

$$
\int_{\underline{y}}^{\bar{y}} \omega(y) V_{y}^{j}(y) h^{j}(y) a_{j}(y) f(y) \mathrm{d} y+\eta_{j} \int_{\underline{y}}^{\bar{y}} h_{y}^{j}(y) h^{j}(y) a_{j}(y) f(y) \mathrm{d} y=\omega_{R} H^{S}\left(p_{j}\right) .
$$

Substituting this into (17), dropping $y$ as an argument and rearranging terms gives

$$
\int_{\underline{y}}^{\bar{y}} \omega\left[V_{p}^{j}+V_{y}^{j} h^{j}\right] a_{j} f \mathrm{~d} y=-\eta_{j}\left(\int_{\underline{y}}^{\bar{y}}\left[h_{p}^{j}+h_{y}^{j} h^{j}\right] a_{j} f \mathrm{~d} y-H_{p}^{S}\left(p_{j}\right)\right) .
$$

The LHS is zero by Roy's identity. The parenthesis on the RHS consists of the slope of the compensated demand function (averaged over all households), minus the slope of the supply function for housing, and is thus negative. In order for the equation to hold, $\eta_{j}$ therefore has to be zero.

\section{A2. Proof of Proposition 1}

For the special case of a publicly provided private good, substitute $\rho=1, \nu=\sigma=0$ and $g_{j}=\left(t_{j} Y_{j}+N_{j} T_{j}\right) / N_{j}$ into 19$)$ to get

$$
\left.J C E_{j}(y)\right|_{\sigma=\nu=0, \rho=1}=\lambda_{j} t_{j}\left(y-Y_{j} / N_{j}\right)+\eta_{j} h^{j}(y)
$$


Setting $t_{j}=\eta_{j}=0$ immediately leads to part (i). For part (ii), substituting $t_{j}=\eta_{j}=0$ back into (19) leads to

$$
\begin{aligned}
\left.J C E_{j}(y)\right|_{t_{j}=\eta_{j}=0}= & \left(\lambda_{j}+\sigma \sum_{i \neq j} \lambda_{i}\right) T_{j} \\
& -\rho\left(\lambda_{j} \frac{T_{j} N_{j}+\sigma \sum_{i \neq j} T_{i} N_{i}}{N_{j}+\nu \sum_{i \neq j} N_{i}}+\sigma \sum_{i \neq j} \lambda_{i} \frac{T_{i} N_{i}+\sigma \sum_{k \neq i} T_{k} N_{k}}{N_{i}+\nu \sum_{k \neq i} N_{k}}\right)
\end{aligned}
$$

Note that without income taxes, the JCE no longer depends on the income level of the household that is added to municipality $j$. If $\rho$ is sufficiently small relative to $\sigma$, the first part dominates and the JCE is positive, and vice versa. For part (iii), substitute $T_{j}=0$ into 19$)$ and take the derivative with respect to income to get

$$
\frac{\partial J C E_{j}(y)}{\partial y}=\left(\lambda_{j}+\sigma \sum_{i \neq j} \lambda_{i}\right) t_{j}+\eta_{j} \frac{\partial h^{j}(y)}{\partial y}
$$

The first term is positive (note that the congestion-related part is independent of income and therefore drops out). The second term is negative only for $\eta_{j}<0$, which, as discussed above, is the case if the welfare weight placed on the absentee landlords is sufficiently small. Provided that the second effect does not eliminate the first, the JCE increases in income. Part (iv): Suppose that this were not the case, such that $J C E_{j}\left(\tilde{y}_{j, j+1}\right)>J C E_{j+1}\left(\tilde{y}_{j, j+1}\right)$. It would then be possible to reallocate a measure of households in the interval $y \in\left(\tilde{y}_{j, j+1}, \tilde{y}_{j, j+1}+\epsilon\right)$, where $\epsilon$ is small, from municipality $j+1$ to municipality $j$ and thereby increase social welfare. This is impossibly by the definition of a social optimum.

\section{A3. Proof of Proposition 2}

For income-segregated equilibria, (14) can be written without summations terms:

$$
\omega(y) V_{y}^{j}(y)+\eta_{j} h_{y}^{j}(y)=\omega_{R}
$$

Multiplying by $a_{j}(y)$ and integrating over the support of $y$ on both sides leads to

$$
\int_{\underline{y}}^{\bar{y}} \omega(y) V_{y}^{j}(y) a_{j} f(y) \mathrm{d} y+\eta_{j} \int_{\underline{y}}^{\bar{y}} h_{y}^{j}(y) a_{j} f(y) \mathrm{d} y=\omega_{R} N_{j} .
$$


Substituting this expression into 15 while recognizing that $V_{T}\left(1-t_{j}\right)=-V_{y}$ and $h_{T}\left(1-t_{j}\right)=$ $-h_{y}$, and simplifying leads to

$$
\lambda_{j}+\sigma \sum_{i \neq j} \lambda_{i}=\frac{\omega_{R}}{1-t_{j}}
$$

This expression holds for all $j$ and can be solved for ${ }^{38}$

$$
\lambda_{j}=\frac{\omega_{R}}{(1+\sigma(J-1))(1-\sigma)}\left(\frac{1+\sigma(J-2)}{1-t_{j}}-\sigma \sum_{i \neq j} \frac{1}{1-t_{i}}\right)
$$

Substituting (A8) into (18), finally, leads to the following optimality condition:

$$
\begin{aligned}
\int_{\underline{y}}^{\bar{y}} \omega(y) V_{g}^{j}(y) a_{j}(y) f(y) \mathrm{d} y= & \frac{\omega_{R}\left(N_{j}+\nu \sum_{i \neq j} N_{i}\right)^{\rho}}{(1+\sigma(J-1))(1-\sigma)}\left(\frac{1+\sigma(J-2)}{1-t_{j}}-\sigma \sum_{i \neq j} \frac{1}{1-t_{i}}\right) \\
& -\eta_{j} \int_{\underline{y}}^{\bar{y}} h_{g}^{j}(y) a_{j}(y) f(y) \mathrm{d} y .
\end{aligned}
$$

This is a generalized Samuelson condition that defines the efficient production (and consumption) level of the publicly provided good, accounting for imperfect congestion and spillovers. It states that the aggregate social marginal utility from an additional unit of $g_{j}$ (left-hand side) needs to be equal to the sum of total fiscal costs (conditional on the degree of spillovers and congestion) and the inefficiency due to a suboptimal distribution of the population.

To prove Part (i), recall that in the first-best case, $\eta_{j}=t_{j}=0$. Divide the LHS of (A9) by $\int_{y}^{\bar{y}} \omega(y) V_{y}^{j}(y) a_{j}(y) f(y) \mathrm{d} y$, and the RHS by $\omega_{R} N_{j}$, which by are equal, and use 22):

$$
\frac{\int_{\underline{y}}^{\bar{y}} \omega(y) V_{g}^{j}(y) a_{j}(y) f(y) \mathrm{d} y}{\int_{\underline{y}}^{\bar{y}} \omega(y) V_{y}^{j}(y) a_{j}(y) f(y) \mathrm{d} y}=\frac{\lambda\left(N_{j}+\nu \sum_{i \neq j} N_{i}\right)^{\rho}}{\omega_{R} N_{j}} .
$$

From (14), it follows that $\omega(y) V_{y}^{j}(y)=\omega_{R}$. Because this is a constant for all $y$, we can take it inside the integral in the numerator of the LHS and cancel the welfare terms:

$$
\frac{\int_{\underline{y}}^{\bar{y}} \frac{\omega(y) V_{g}^{j}(y)}{\omega_{R}} a_{j}(y) f(y) \mathrm{d} y}{\int_{\underline{y}}^{\bar{y}} a_{j} f(y) \mathrm{d} y}=\frac{\int_{\underline{y}}^{\bar{y}} \frac{\omega(y) V_{g}^{j}(y)}{\omega(y) V_{y}^{j}(y)} a_{j}(y) f(y) \mathrm{d} y}{N_{j}}=\frac{\int_{\underline{y}}^{\bar{y}} \frac{V_{g}^{j}(y)}{V_{y}^{j}(y)} a_{j}(y) f(y) \mathrm{d} y}{N_{j}}
$$

\footnotetext{
${ }^{38}$ To arrive at $(\mathrm{A} 8$, set up the system of equations of $\mathrm{A} 7 \mathrm{f}$ for $J=2,3, \ldots$ and solve it manually. This reveals the general formula.
} 
Setting this equal to the RHS in A10 and multiplying by $N_{j}$ leads to (21).

Part (ii) of the proposition follows directly from substituting $t_{j}=0$ into $(\mathrm{A} 8)$.

\section{A4. Additional tables and figures}

Table A1: First-best efficiency conditions for the given functional forms.

\begin{tabular}{|c|c|}
\hline $\begin{array}{l}\text { Choice } \\
\text { variables }\end{array}$ & Efficiency conditions \\
\hline$t_{j}$ & $0=\int_{y}^{\bar{y}} \omega(y) V_{t}^{j}(y) a_{j} f(y) \mathrm{d} y+\eta_{j} \int_{y}^{\bar{y}} h_{t}^{j}(y) a_{j} f(y) \mathrm{d} y+Y_{j}\left(\lambda_{j}+\sigma \sum_{i \neq j} \lambda_{i}\right)$ \\
\hline$T_{j}$ & $0=\int_{\underline{y}}^{\bar{y}} \omega(y) V_{T}^{j}(y) a_{j} f(y) \mathrm{d} y+\eta_{j} \int_{\underline{y}}^{\overline{\bar{y}}} h_{T}^{j}(y) a_{j} f(y) \mathrm{d} y+N_{j}\left(\lambda_{j}+\sigma \sum_{i \neq j} \lambda_{i}\right)$ \\
\hline$p_{j}$ & $0=\int_{\underline{y}}^{\bar{y}} \omega(y) V_{p}^{j}(y) a_{j} f(y) \mathrm{d} y+\eta_{j}\left(\int_{\underline{y}}^{\bar{y}} h_{p}^{j}(y) a_{j} f(y) \mathrm{d} y-H_{p}^{S}\left(p_{j}\right)\right)+\omega_{R} H^{S}\left(p_{j}\right)$ \\
\hline$g_{j}$ & $0=\int_{\underline{y}}^{\bar{y}} \omega(y) V_{g}^{j}(y) a_{j} f(y) \mathrm{d} y+\eta_{j} \int_{\underline{y}}^{\bar{y}} h_{g}^{j}(y) a_{j} f(y) \mathrm{d} y-\lambda_{j}\left(N_{j}+\nu \sum_{i \neq j} N_{i}\right)^{\rho}$ \\
\hline$r(y)$ & 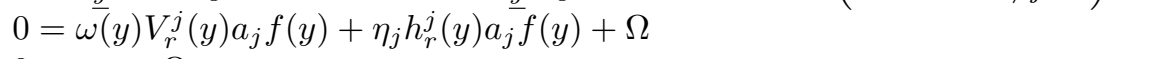 \\
\hline & $0=\omega_{R}+\Omega$ \\
\hline$y_{i, j}^{b o r d e r}$ & $0=M S V_{i}\left(y_{i, j}^{\text {border }}\right)-M S V_{j}\left(y_{i, j}^{\text {border }}\right)$ \\
\hline $\begin{array}{l}\text { Shadow } \\
\text { variables }\end{array}$ & Feasibility constraints \\
\hline$\lambda_{j}$ & $0=t_{j} Y_{j}+T_{j} N_{j}+\sigma \sum_{i \neq j}\left(t_{i} Y_{i}+T_{i} N_{i}\right)-g_{j} \cdot\left(N_{j}+\nu \sum_{i \neq j} N_{i}\right)^{\rho}$ \\
\hline$\eta_{j}$ & $0=\int_{\underline{y}}^{\bar{y}} h^{j}(y) a_{j}(y) f(y) \mathrm{d} y-H^{S}\left(p_{j}\right)$ \\
\hline$\Omega$ & $0=\underline{R}+\int_{\underline{y}}^{\bar{y}} r(y) f(y) \mathrm{d} y$ \\
\hline $\begin{array}{l}\text { First } \\
\text { derivatives }\end{array}$ & Functional forms \\
\hline$V_{y}^{j}$ & $0=\frac{(1-\alpha)\left(1-t_{j}\right)}{y\left(1-t_{j}\right)+r(y)-T_{j}-p_{j} \beta_{h}-\beta_{x}}-V_{y}^{j}$ \\
\hline$V_{t}^{j}$ & $0=-\frac{\left.y\left(1-t_{j}\right)+r(y)-1-\alpha\right) y}{y\left(1-t_{j}\right)+r(y)-T_{i}-p_{j} \beta_{h}-\beta_{x}}-V_{t}^{j}$ \\
\hline$V_{T}^{j}$ & $0=-\frac{y\left(1-t_{j}\right)+r(y)-T_{j}-p_{j} \beta_{h}-\beta_{x}}{y\left(1-t_{j}\right)+r(y)-T_{j}-p_{j} \beta_{h}-\beta_{x}}-V_{T}^{j}$ \\
\hline$V_{r}^{j}$ & $\begin{array}{l}0=-\overline{y\left(1-t_{j}\right)+r(y)-T_{j}-p_{j} \beta_{h}-\beta_{x}}-V_{T} \\
0=\frac{(1-\alpha)}{u\left(1-t_{j}\right)+r(1)-T_{j}-p_{j} \beta_{h}-\beta_{x}}-V_{r}^{j}\end{array}$ \\
\hline$V_{p}^{j}$ & 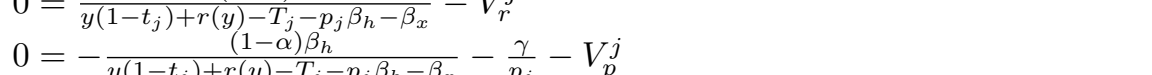 \\
\hline$V_{g}^{j}$ & $\begin{array}{l}0=-\overline{y\left(1-t_{j}\right)+r(y)-T_{j}-p_{j} \beta_{h}-\beta_{x}}-\frac{\overline{p_{j}}}{p_{j}}-V_{p}^{j} \\
0=\frac{\alpha}{g_{j}-\beta_{g}}-V_{g}^{j}\end{array}$ \\
\hline$h_{t}^{j}$ & 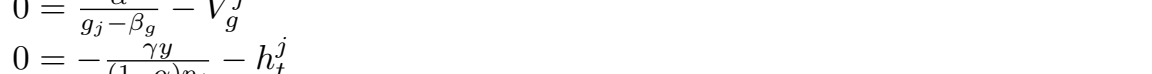 \\
\hline$h_{T}^{j}$ & $\begin{array}{l}0=-\frac{\gamma y}{(1-\alpha) p_{j}}-h_{t}^{J} \\
0=-\frac{\gamma}{2}-h^{j}\end{array}$ \\
\hline$h_{p}^{j}$ & $0=-\frac{\gamma}{(1-\alpha) p_{j}}-h_{T}^{j}$ \\
\hline $\begin{array}{l}\omega_{p} \\
h_{a}^{j}\end{array}$ & $0=-\gamma \frac{y\left(1-t_{j}\right)+r(y)-T_{j}-\beta_{x}}{(1-\alpha) p_{j}^{2}}-h_{p}^{j}$ \\
\hline $\begin{array}{l}n_{g}^{\prime} \\
h_{r}^{j}\end{array}$ & $\begin{array}{l}0=h_{g}^{j} \\
0=\frac{\gamma}{(1-\alpha) n_{i}}-h_{r}^{j}\end{array}$ \\
\hline$H_{p_{j}}^{S}$ & $0=\theta L_{j} p_{j}^{\theta-1}-H_{p_{j}}^{S}$ \\
\hline
\end{tabular}

Notes. $H^{S}\left(p_{j}\right)=L_{j} p_{j}^{\theta}$ and $M S V_{j}\left(y_{i, j}^{\text {border }}\right)$ is given by 13 for $y=y_{i, j}^{\text {border }}$. 
Table A2: First-best vs. decentralized eqilibrium: Publicly provided private good.

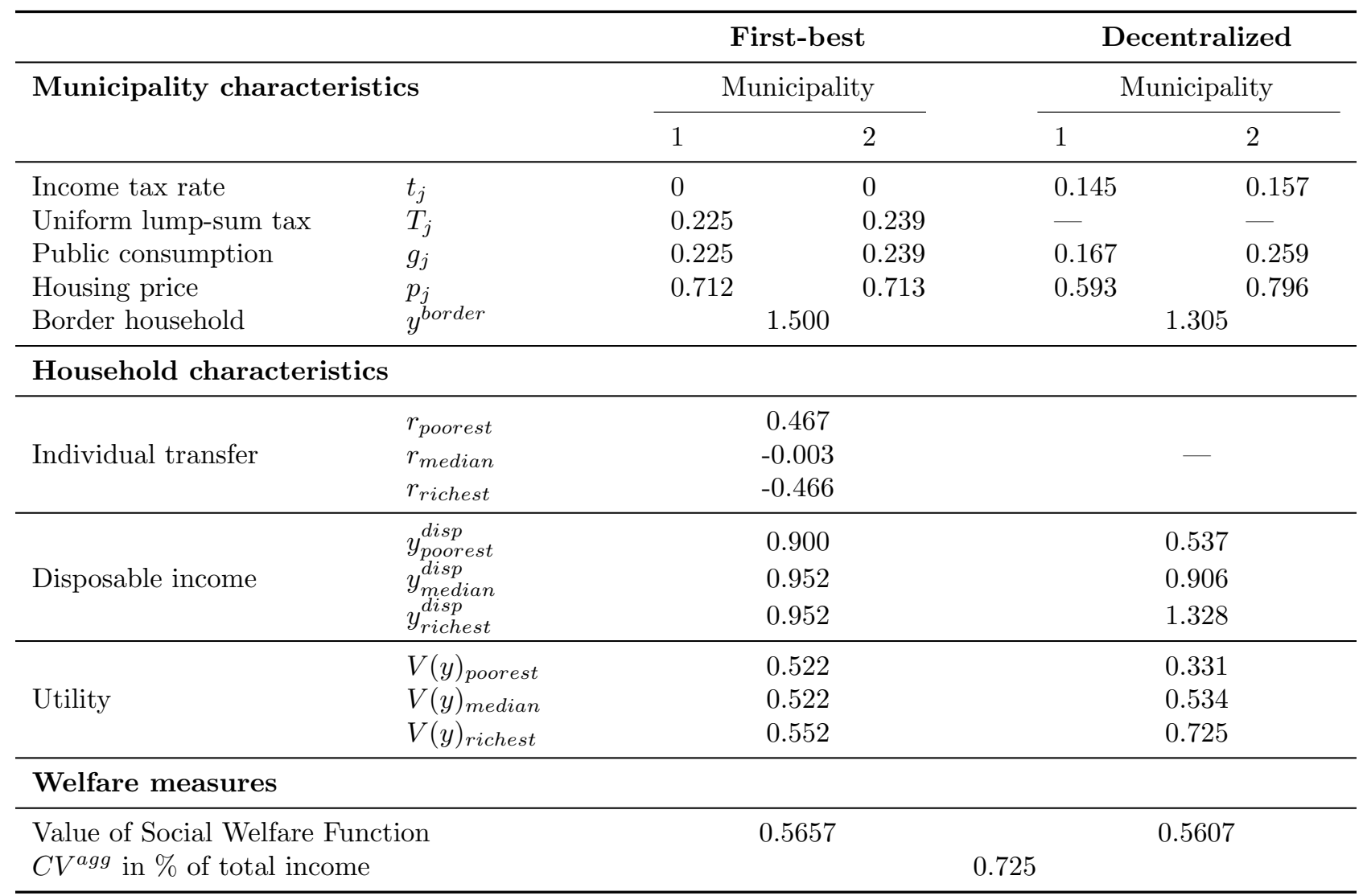

Results are for $\sigma=0$ and $\rho=1$. Households are uniformly distributed between $\underline{y}=1$ and $\bar{y}=2$. Integrals are approximated by modeling 101 household types with income $y=1,1.01,1.02, \ldots, 2$. 
Table A3: Decentralized equilibrium results for different values of $\sigma$ and $\rho$.

\begin{tabular}{|c|c|c|c|c|c|c|c|c|}
\hline & & $j$ & $\overline{y_{j}}$ & $Y_{j}$ & $p_{j}$ & $t_{j}$ & $G_{j}$ & $g_{j}$ \\
\hline \multirow{4}{*}{$\sigma=0$} & \multirow{2}{*}{$\rho=1$} & 1 & 1.305 & 0.352 & 0.593 & 0.145 & 0.051 & 0.167 \\
\hline & & 2 & 2 & 1.148 & 0.796 & 0.157 & 0.180 & 0.259 \\
\hline & \multirow{2}{*}{$\rho \leq 0.65$} & 1 & 1 & 0 & 0.007 & 0.158 & 0 & 0.006 \\
\hline & & 2 & 2 & 1.500 & 0.870 & 0.150 & 0.225 & 0.225 \\
\hline \multirow{6}{*}{$\sigma=0.1$} & \multirow{2}{*}{$\rho=1$} & 1 & 1.369 & 0.437 & 0.632 & 0.115 & 0.050 & 0.154 \\
\hline & & 2 & 2 & 1.063 & 0.777 & 0.154 & 0.164 & 0.253 \\
\hline & \multirow{2}{*}{$\rho=0.5$} & 1 & 1.159 & 0.171 & 0.495 & 0.050 & 0.008 & 0.058 \\
\hline & & 2 & 2 & 1.329 & 0.835 & 0.153 & 0.203 & 0.221 \\
\hline & \multirow{2}{*}{$\rho=0$} & 1 & 1.022 & 0.022 & 0.285 & 0 & 0 & 0.022 \\
\hline & & 2 & 2 & 1.478 & 0.865 & 0.151 & 0.224 & 0.224 \\
\hline \multirow{6}{*}{$\sigma=0.3$} & \multirow{2}{*}{$\rho=1$} & 1 & 1.479 & 0.594 & 0.690 & 0.092 & 0.055 & 0.148 \\
\hline & & 2 & 2 & 0.906 & 0.742 & 0.145 & 0.132 & 0.223 \\
\hline & \multirow{2}{*}{$\rho=0.5$} & 1 & 1.457 & 0.561 & 0.680 & 0.086 & 0.048 & 0.114 \\
\hline & & 2 & 2 & 0.939 & 0.749 & 0.147 & 0.138 & 0.185 \\
\hline & \multirow{2}{*}{$\rho=0$} & 1 & 1.346 & 0.406 & 0.628 & 0.045 & 0.018 & 0.069 \\
\hline & & 2 & 2 & 1.094 & 0.784 & 0.153 & 0.168 & 0.173 \\
\hline \multirow{7}{*}{$\sigma=0.5$} & \multirow{2}{*}{$\rho=1$} & 1 & 1.555 & 0.709 & 0.724 & 0.088 & 0.062 & 0.146 \\
\hline & & 2 & 2 & 0.791 & 0.715 & 0.130 & 0.103 & 0.185 \\
\hline & \multirow{2}{*}{$\rho=0.5$} & 1 & 1.572 & 0.736 & 0.730 & 0.094 & 0.069 & 0.132 \\
\hline & & 2 & 2 & 0.764 & 0.708 & 0.126 & 0.096 & 0.155 \\
\hline & \multirow{2}{*}{$\rho=0.15$} & 1 & 1.592 & 0.768 & 0.738 & 0.101 & 0.077 & 0.125 \\
\hline & & 2 & 2 & 0.732 & 0.700 & 0.120 & 0.088 & 0.133 \\
\hline & \multicolumn{3}{|l|}{$\rho \leq 0.1$} & \multicolumn{4}{|c|}{ No income separating equilibrium found. } & \\
\hline \multirow{5}{*}{$\sigma=0.7$} & \multirow{2}{*}{$\rho=1$} & 1 & 1.590 & 0.764 & 0.739 & 0.086 & 0.065 & 0.141 \\
\hline & & 2 & 2 & 0.736 & 0.703 & 0.112 & 0.083 & 0.156 \\
\hline & \multirow{2}{*}{$\rho=0.6$} & 1 & 1.595 & 0.772 & 0.740 & 0.088 & 0.068 & 0.134 \\
\hline & & 2 & 2 & 0.728 & 0.701 & 0.110 & 0.080 & 0.144 \\
\hline & \multicolumn{3}{|l|}{$\rho \leq 0.55$} & \multicolumn{4}{|c|}{ No income separating equilibrium found. } & \\
\hline \multirow{3}{*}{$\sigma=0.78$} & \multirow{2}{*}{$\rho=1$} & 1 & 1.596 & 0.774 & 0.741 & 0.084 & 0.065 & 0.138 \\
\hline & & 2 & 2 & 0.726 & 0.701 & 0.106 & 0.077 & 0.147 \\
\hline & \multicolumn{3}{|l|}{$\rho \leq 0.95$} & \multicolumn{4}{|c|}{ No income separating equilibrium found. } & \\
\hline \multicolumn{4}{|l|}{$\sigma \geq 0.8$} & \multicolumn{4}{|c|}{ No income separating equilibrium found. } & \\
\hline
\end{tabular}

Definition of parameters. $\sigma$ : spillover parameter (0: no spillover, 1 : perfect spillover); $\rho$ : parameter for rivalry in consumption (0: no rivalry, 1: perfect rivalry). Definition of variables. $\overline{y_{j}}$ : highest income household in $\mathrm{j}$ (municipality 1 has poor households and municipality 2 rich households; $\overline{y_{1}}=y_{2}$ is the indifferent household); $Y_{j}$ : aggregate income; $p_{j}$ : housing price; $t_{j}$ : income tax rate; $G_{j}$ : contribution to publicly provided good; $g_{j}$ : consumption of publicly provided good. 
Table A4: First-best equilibrium results for different values of $\sigma$ and $\rho$.

\begin{tabular}{|c|c|c|c|c|c|c|c|c|}
\hline & & $j$ & $\overline{y_{j}}$ & $Y_{j}$ & $p_{j}$ & $T_{j}$ & $g_{j}$ & $\begin{array}{l}C V^{a g g} \\
\text { (\% of total income) }\end{array}$ \\
\hline \multirow[t]{3}{*}{$\sigma=0$} & $\rho=1$ & $\begin{array}{l}1 \\
2\end{array}$ & $\begin{array}{l}1.5 \\
2\end{array}$ & $\begin{array}{l}0.625 \\
0.875\end{array}$ & $\begin{array}{l}0.712 \\
0.713\end{array}$ & $\begin{array}{l}0.225 \\
0.239\end{array}$ & $\begin{array}{l}0.225 \\
0.239\end{array}$ & 0.725 \\
\hline & $\rho=0.5$ & $\begin{array}{l}1 \\
2\end{array}$ & $\begin{array}{l}1.06 \\
2\end{array}$ & $\begin{array}{l}0.062 \\
1.438\end{array}$ & $\begin{array}{l}0.323 \\
0.859\end{array}$ & $\begin{array}{l}0 \\
0.244\end{array}$ & $\begin{array}{l}0.016 \\
0.237\end{array}$ & 1.062 \\
\hline & $\rho=0$ & $\begin{array}{l}1 \\
2\end{array}$ & $\begin{array}{l}1.02 \\
2\end{array}$ & $\begin{array}{l}0.02 \\
1.48\end{array}$ & $\begin{array}{l}0.235 \\
0.866\end{array}$ & $\begin{array}{l}0 \\
0.233\end{array}$ & $\begin{array}{l}0.005 \\
0.229\end{array}$ & 0.457 \\
\hline \multirow[t]{3}{*}{$\sigma=0.1$} & $\rho=1$ & $\begin{array}{l}1 \\
2\end{array}$ & $\begin{array}{l}1.48 \\
2\end{array}$ & $\begin{array}{l}0.595 \\
0.905\end{array}$ & $\begin{array}{l}0.699 \\
0.726\end{array}$ & $\begin{array}{l}0.205 \\
0.257\end{array}$ & $\begin{array}{l}0.21 \\
0.252\end{array}$ & 0.438 \\
\hline & $\rho=0.5$ & $\begin{array}{l}1 \\
2\end{array}$ & $\begin{array}{l}1.12 \\
2\end{array}$ & $\begin{array}{l}0.127 \\
1.373\end{array}$ & $\begin{array}{l}0.42 \\
0.847\end{array}$ & 0.262 & $\begin{array}{l}0.051 \\
0.244\end{array}$ & 0.739 \\
\hline & $\rho=0$ & $\begin{array}{l}1 \\
2\end{array}$ & $\begin{array}{l}1.02 \\
2\end{array}$ & $\begin{array}{l}0.02 \\
1.48\end{array}$ & $\begin{array}{l}0.256 \\
0.865\end{array}$ & $\begin{array}{l}0 \\
0.233\end{array}$ & $\begin{array}{l}0.023 \\
0.229\end{array}$ & 0.090 \\
\hline \multirow[t]{3}{*}{$\sigma=0.3$} & $\rho=1$ & $\begin{array}{l}1 \\
2\end{array}$ & $\begin{array}{l}1.34 \\
2\end{array}$ & $\begin{array}{l}0.398 \\
1.102\end{array}$ & $\begin{array}{l}0.601 \\
0.79\end{array}$ & $\begin{array}{l}0 \\
0.354\end{array}$ & $\begin{array}{l}0.13 \\
0.307\end{array}$ & 1.387 \\
\hline & $\rho=0.5$ & $\begin{array}{l}1 \\
2\end{array}$ & $\begin{array}{l}1.2 \\
2\end{array}$ & $\begin{array}{l}0.22 \\
1.28\end{array}$ & $\begin{array}{l}0.516 \\
0.825\end{array}$ & $\begin{array}{l}0 \\
0.29\end{array}$ & $\begin{array}{l}0.105 \\
0.25\end{array}$ & 2.238 \\
\hline & $\rho=0$ & $\begin{array}{l}1 \\
2\end{array}$ & $\begin{array}{l}1.02 \\
2\end{array}$ & $\begin{array}{l}0.02 \\
1.48\end{array}$ & $\begin{array}{l}0.289 \\
0.864\end{array}$ & $\begin{array}{l}0 \\
0.233\end{array}$ & $\begin{array}{l}0.069 \\
0.229\end{array}$ & 3.978 \\
\hline \multirow[t]{3}{*}{$\sigma=0.5$} & $\rho=1$ & $\begin{array}{l}1 \\
2\end{array}$ & $\begin{array}{l}1.36 \\
2\end{array}$ & $\begin{array}{l}0.425 \\
1.075\end{array}$ & $\begin{array}{l}0.629 \\
0.776\end{array}$ & $\begin{array}{l}0 \\
0.365\end{array}$ & $\begin{array}{l}0.172 \\
0.285\end{array}$ & 2.018 \\
\hline & $\rho=0.5$ & $\begin{array}{l}1 \\
2\end{array}$ & $\begin{array}{l}1.28 \\
2\end{array}$ & $\begin{array}{l}0.319 \\
1.181\end{array}$ & $\begin{array}{l}0.584 \\
0.8\end{array}$ & $\begin{array}{l}0 \\
0.324\end{array}$ & $\begin{array}{l}0.146 \\
0.251\end{array}$ & 2.470 \\
\hline & $\rho=0$ & $\begin{array}{l}1 \\
2\end{array}$ & $\begin{array}{l}1.12 \\
2\end{array}$ & $\begin{array}{l}0.127 \\
1.373\end{array}$ & $\begin{array}{l}0.459 \\
0.841\end{array}$ & $\begin{array}{l}0 \\
0.262\end{array}$ & $\begin{array}{l}0.115 \\
0.231\end{array}$ & - \\
\hline \multirow[t]{3}{*}{$\sigma=0.7$} & $\rho=1$ & $\begin{array}{l}1 \\
2\end{array}$ & $\begin{array}{l}1.38 \\
2\end{array}$ & $\begin{array}{l}0.452 \\
1.048\end{array}$ & $\begin{array}{l}0.651 \\
0.763\end{array}$ & $\begin{array}{l}0 \\
0.377\end{array}$ & $\begin{array}{l}0.201 \\
0.264\end{array}$ & 2.545 \\
\hline & $\rho=0.5$ & $\begin{array}{l}1 \\
2 \\
\end{array}$ & $\begin{array}{l}1.34 \\
2 \\
\end{array}$ & $\begin{array}{l}0.398 \\
1.102 \\
\end{array}$ & $\begin{array}{l}0.63 \\
0.777 \\
\end{array}$ & $\begin{array}{l}0 \\
0.354 \\
\end{array}$ & $\begin{array}{l}0.183 \\
0.246 \\
\end{array}$ & 2.618 \\
\hline & $\rho=0$ & $\begin{array}{l}1 \\
2\end{array}$ & $\begin{array}{l}1.26 \\
2\end{array}$ & $\begin{array}{l}0.294 \\
1.206\end{array}$ & $\begin{array}{l}0.583 \\
0.801\end{array}$ & $\begin{array}{l}0 \\
0.315\end{array}$ & $\begin{array}{l}0.163 \\
0.233\end{array}$ & - \\
\hline \multirow[t]{3}{*}{$\sigma=1$} & $\rho=1$ & $\begin{array}{l}1 \\
2\end{array}$ & $\begin{array}{l}1.5 \\
2\end{array}$ & $\begin{array}{l}0.625 \\
0.875\end{array}$ & $\begin{array}{l}0.715 \\
0.711\end{array}$ & $\begin{array}{l}0 \\
0.468\end{array}$ & $\begin{array}{l}0.234 \\
0.234\end{array}$ & - \\
\hline & $\rho=0.5$ & $\begin{array}{l}1 \\
2\end{array}$ & $\begin{array}{l}1.5 \\
2\end{array}$ & $\begin{array}{l}0.625 \\
0.875\end{array}$ & $\begin{array}{l}0.715 \\
0.711\end{array}$ & $\begin{array}{l}0 \\
0.468\end{array}$ & $\begin{array}{l}0.234 \\
0.234\end{array}$ & - \\
\hline & $\rho=0$ & $\begin{array}{l}1 \\
2\end{array}$ & $\begin{array}{l}1.5 \\
2\end{array}$ & $\begin{array}{l}0.625 \\
0.875\end{array}$ & $\begin{array}{l}0.715 \\
0.711\end{array}$ & $\begin{array}{l}0 \\
0.468\end{array}$ & $\begin{array}{l}0.234 \\
0.234\end{array}$ & - \\
\hline
\end{tabular}

Definition of parameters and variables. As in Table A3. $T_{j}$ : lump-sum tax; $C V^{a g g}$ in $\%$ of total income: Aggregate compensating variation in \% of aggregate income (welfare loss of decentralization).

Note. $\mathrm{CV}$ for $(\sigma=0.7, \rho=0.5)$ is for $\sigma=0.68$ because no SB equilibrium was found for $\sigma=0.7$. 
Table A5: Decomposition of the welfare loss with local social planners (LSPs) for the baseline values of $\sigma$ and $\rho$.

\begin{tabular}{|c|c|c|c|c|c|c|}
\hline & $j$ & $p_{j}$ & $t_{j}$ & $g_{j}$ & $S W F$ & $C V^{a g g}$ \\
\hline \multirow{2}{*}{ II } & 1 & 0.597 & 0.006 & 0.081 & \multirow{2}{*}{0.5456} & \multirow{2}{*}{0.711} \\
\hline & 2 & 0.801 & 0.156 & 0.206 & & \\
\hline \multirow{2}{*}{ II \& LSP1 } & 1 & 0.596 & 0.011 & 0.083 & \multirow{2}{*}{0.5455} & \multirow{2}{*}{0.713} \\
\hline & 2 & 0.801 & 0.156 & 0.206 & & \\
\hline \multirow{2}{*}{ II \& LSP2 } & 1 & 0.597 & 0.006 & 0.081 & \multirow{2}{*}{0.5455} & \multirow{2}{*}{0.716} \\
\hline & 2 & 0.801 & 0.158 & 0.209 & & \\
\hline
\end{tabular}

Definition of parameters and variables. As in Table A4 SWF: Level of the social welfare function.

Note. This table resembles version II from Table 3. "II \& LSP1" indicates that in municipality 1 the tax rate (and therefore the public provision level) has been determined by a local social planner, taking the majority voting decision and the population distribution in municipality 2 as given. "II \& LSP2" indicates the respective case for a local social planner in municipality 2 . 
Table A6: Sensitivity analysis by model version: Municipality characteristics and Compansating variation for $\sigma=0.3$ and $\rho=0.5$.

\begin{tabular}{|c|c|c|c|c|c|c|c|c|c|c|c|c|c|c|c|}
\hline & $j$ & $y^{\text {bord }}$ & $Y_{j}$ & $p_{j}$ & $T_{j}$ & $t_{j}$ & $g_{j}$ & $C V^{a g g}$ & $y^{\text {bord }}$ & $Y_{j}$ & $p_{j}$ & $T_{j}$ & $t_{j}$ & $g_{j}$ & $C V^{a g g}$ \\
\hline & & \multicolumn{7}{|c|}{ First best } & \multicolumn{7}{|c|}{ Version I } \\
\hline Baseline & $\begin{array}{l}1 \\
2\end{array}$ & $\begin{array}{l}1.21 \\
2\end{array}$ & $\begin{array}{l}0.232 \\
1.268\end{array}$ & $\begin{array}{l}0.523 \\
0.823\end{array}$ & $\begin{array}{l}0.000 \\
0.294\end{array}$ & $\begin{array}{l}0.000 \\
0.000\end{array}$ & $\begin{array}{l}0.104 \\
0.251\end{array}$ & 2.258 & $\begin{array}{l}1.18 \\
2\end{array}$ & $\begin{array}{l}0.196 \\
1.304\end{array}$ & $\begin{array}{l}0.526 \\
0.824\end{array}$ & $\begin{array}{l}0.000 \\
0.000\end{array}$ & $\begin{array}{l}0.000 \\
0.175\end{array}$ & $\begin{array}{l}0.105 \\
0.244\end{array}$ & 1.394 \\
\hline$\theta=1.5$ & $\begin{array}{l}1 \\
2\end{array}$ & $\begin{array}{l}1.26 \\
2\end{array}$ & $\begin{array}{l}0.294 \\
1.206\end{array}$ & $\begin{array}{l}0.359 \\
0.693\end{array}$ & $\begin{array}{l}0.000 \\
0.323\end{array}$ & $\begin{array}{l}0.000 \\
0.000\end{array}$ & $\begin{array}{l}0.103 \\
0.264\end{array}$ & 1.799 & $\begin{array}{l}1.22 \\
2\end{array}$ & $\begin{array}{l}0.244 \\
1.256\end{array}$ & $\begin{array}{l}0.366 \\
0.695\end{array}$ & $\begin{array}{l}0.000 \\
0.000\end{array}$ & $\begin{array}{l}0.000 \\
0.186\end{array}$ & $\begin{array}{l}0.104 \\
0.255\end{array}$ & 0.913 \\
\hline$\theta=3.5$ & $\begin{array}{l}1 \\
2\end{array}$ & $\begin{array}{l}1.19 \\
2\end{array}$ & $\begin{array}{l}0.208 \\
1.292\end{array}$ & $\begin{array}{l}0.554 \\
0.847\end{array}$ & $\begin{array}{l}0.000 \\
0.285\end{array}$ & $\begin{array}{l}0.000 \\
0.000\end{array}$ & $\begin{array}{l}0.105 \\
0.248\end{array}$ & 1.801 & $\begin{array}{l}1.17 \\
2\end{array}$ & $\begin{array}{l}0.184 \\
1.316\end{array}$ & $\begin{array}{l}0.561 \\
0.847\end{array}$ & $\begin{array}{l}0.000 \\
0.000\end{array}$ & $\begin{array}{l}0.000 \\
0.173\end{array}$ & $\begin{array}{l}0.105 \\
0.242\end{array}$ & 1.213 \\
\hline$\alpha$ low & $\begin{array}{l}1 \\
2\end{array}$ & $\begin{array}{l}1.24 \\
2\end{array}$ & $\begin{array}{l}0.269 \\
1.231\end{array}$ & $\begin{array}{l}0.543 \\
0.815\end{array}$ & $\begin{array}{l}0.000 \\
0.245\end{array}$ & $\begin{array}{l}0.000 \\
0.000\end{array}$ & $\begin{array}{l}0.082 \\
0.204\end{array}$ & 1.650 & $\begin{array}{l}1.21 \\
2\end{array}$ & $\begin{array}{l}0.232 \\
1.268\end{array}$ & $\begin{array}{l}0.546 \\
0.816\end{array}$ & $\begin{array}{l}0.000 \\
0.000\end{array}$ & $\begin{array}{l}0.000 \\
0.145\end{array}$ & $\begin{array}{l}0.082 \\
0.199\end{array}$ & 0.991 \\
\hline$\alpha$ high & $\begin{array}{l}1 \\
2\end{array}$ & $\begin{array}{l}1.18 \\
2\end{array}$ & $\begin{array}{l}0.196 \\
1.304\end{array}$ & $\begin{array}{l}0.501 \\
0.830\end{array}$ & $\begin{array}{l}0.000 \\
0.339\end{array}$ & $\begin{array}{l}0.000 \\
0.000\end{array}$ & $\begin{array}{l}0.128 \\
0.297\end{array}$ & 2.854 & $\begin{array}{l}1.15 \\
2\end{array}$ & $\begin{array}{l}0.161 \\
1.339\end{array}$ & $\begin{array}{l}0.503 \\
0.831\end{array}$ & $\begin{array}{l}0.000 \\
0.000\end{array}$ & $\begin{array}{l}0.000 \\
0.204\end{array}$ & $\begin{array}{l}0.129 \\
0.288\end{array}$ & 1.762 \\
\hline$\gamma$ low & $\begin{array}{l}1 \\
2\end{array}$ & $\begin{array}{l}1.19 \\
2\end{array}$ & $\begin{array}{l}0.208 \\
1.292\end{array}$ & $\begin{array}{l}0.495 \\
0.806\end{array}$ & $\begin{array}{l}0.000 \\
0.287\end{array}$ & $\begin{array}{l}0.000 \\
0.000\end{array}$ & $\begin{array}{l}0.106 \\
0.250\end{array}$ & 2.332 & $\begin{array}{l}1.17 \\
2\end{array}$ & $\begin{array}{l}0.184 \\
1.316\end{array}$ & $\begin{array}{l}0.503 \\
0.806\end{array}$ & $\begin{array}{l}0.000 \\
0.000\end{array}$ & $\begin{array}{l}0.000 \\
0.174\end{array}$ & $\begin{array}{l}0.106 \\
0.244\end{array}$ & 1.436 \\
\hline$\gamma$ high & $\begin{array}{l}1 \\
2\end{array}$ & $\begin{array}{l}1.22 \\
2\end{array}$ & $\begin{array}{l}0.244 \\
1.256\end{array}$ & $\begin{array}{l}0.543 \\
0.840\end{array}$ & $\begin{array}{l}0.000 \\
0.297\end{array}$ & $\begin{array}{l}0.000 \\
0.000\end{array}$ & $\begin{array}{l}0.103 \\
0.252\end{array}$ & 2.183 & $\begin{array}{l}1.19 \\
2\end{array}$ & $\begin{array}{l}0.208 \\
1.292\end{array}$ & $\begin{array}{l}0.548 \\
0.840\end{array}$ & $\begin{array}{l}0.000 \\
0.000\end{array}$ & $\begin{array}{l}0.000 \\
0.176\end{array}$ & $\begin{array}{l}0.104 \\
0.244\end{array}$ & 1.347 \\
\hline$\beta_{x}$ low & $\begin{array}{l}1 \\
2\end{array}$ & $\begin{array}{l}1.2 \\
2\end{array}$ & $\begin{array}{l}0.220 \\
1.280\end{array}$ & $\begin{array}{l}0.518 \\
0.828\end{array}$ & $\begin{array}{l}0.000 \\
0.300\end{array}$ & $\begin{array}{l}0.000 \\
0.000\end{array}$ & $\begin{array}{l}0.109 \\
0.259\end{array}$ & 2.291 & $\begin{array}{l}1.17 \\
2\end{array}$ & $\begin{array}{l}0.184 \\
1.316\end{array}$ & $\begin{array}{l}0.521 \\
0.830\end{array}$ & $\begin{array}{l}0.000 \\
0.000\end{array}$ & $\begin{array}{l}0.000 \\
0.180\end{array}$ & $\begin{array}{l}0.109 \\
0.252\end{array}$ & 1.431 \\
\hline$\beta_{x}$ high & $\begin{array}{l}1 \\
2\end{array}$ & $\begin{array}{l}1.21 \\
2\end{array}$ & $\begin{array}{l}0.232 \\
1.268\end{array}$ & $\begin{array}{l}0.521 \\
0.819\end{array}$ & $\begin{array}{l}0.000 \\
0.284\end{array}$ & $\begin{array}{l}0.000 \\
0.000\end{array}$ & $\begin{array}{l}0.101 \\
0.243\end{array}$ & 2.205 & $\begin{array}{l}1.18 \\
2\end{array}$ & $\begin{array}{l}0.196 \\
1.304\end{array}$ & $\begin{array}{l}0.522 \\
0.821\end{array}$ & $\begin{array}{l}0.000 \\
0.000\end{array}$ & $\begin{array}{l}0.000 \\
0.169\end{array}$ & $\begin{array}{l}0.101 \\
0.236\end{array}$ & 1.346 \\
\hline$\beta_{h}$ low & $\begin{array}{l}1 \\
2\end{array}$ & $\begin{array}{l}1.18 \\
2\end{array}$ & $\begin{array}{l}0.196 \\
1.304\end{array}$ & $\begin{array}{l}0.487 \\
0.804\end{array}$ & $\begin{array}{l}0.000 \\
0.291\end{array}$ & $\begin{array}{l}0.000 \\
0.000\end{array}$ & $\begin{array}{l}0.110 \\
0.255\end{array}$ & 2.403 & $\begin{array}{l}1.16 \\
2\end{array}$ & $\begin{array}{l}0.173 \\
1.327\end{array}$ & $\begin{array}{l}0.496 \\
0.803\end{array}$ & $\begin{array}{l}0.000 \\
0.000\end{array}$ & $\begin{array}{l}0.000 \\
0.177\end{array}$ & $\begin{array}{l}0.110 \\
0.250\end{array}$ & 1.601 \\
\hline$\beta_{h}$ high & $\begin{array}{l}1 \\
2\end{array}$ & $\begin{array}{l}1.23 \\
2\end{array}$ & $\begin{array}{l}0.256 \\
1.244\end{array}$ & $\begin{array}{l}0.552 \\
0.841\end{array}$ & $\begin{array}{l}0.000 \\
0.293\end{array}$ & $\begin{array}{l}0.000 \\
0.000\end{array}$ & $\begin{array}{l}0.100 \\
0.246\end{array}$ & 2.120 & $\begin{array}{l}1.2 \\
2\end{array}$ & $\begin{array}{l}0.220 \\
1.280\end{array}$ & $\begin{array}{l}0.556 \\
0.842\end{array}$ & $\begin{array}{l}0.000 \\
0.000\end{array}$ & $\begin{array}{l}0.000 \\
0.173\end{array}$ & $\begin{array}{l}0.100 \\
0.238\end{array}$ & 1.190 \\
\hline WWs inc & $\begin{array}{l}1 \\
2\end{array}$ & $\begin{array}{l}1.68 \\
2\end{array}$ & $\begin{array}{l}0.911 \\
0.589\end{array}$ & $\begin{array}{l}0.657 \\
0.752\end{array}$ & $\begin{array}{l}0.000 \\
0.754\end{array}$ & $\begin{array}{l}0.000 \\
0.000\end{array}$ & $\begin{array}{l}0.082 \\
0.333\end{array}$ & 6.099 & $\begin{array}{l}1.88 \\
2\end{array}$ & $\begin{array}{l}1.267 \\
0.233\end{array}$ & $\begin{array}{l}0.824 \\
0.521\end{array}$ & $\begin{array}{l}0.000 \\
0.000\end{array}$ & $\begin{array}{l}0.207 \\
0.000\end{array}$ & $\begin{array}{l}0.273 \\
0.127\end{array}$ & -0.191 \\
\hline \multirow[t]{2}{*}{ WWs dec } & $\begin{array}{l}1 \\
2\end{array}$ & $\begin{array}{l}1.33 \\
2\end{array}$ & $\begin{array}{l}0.384 \\
1.116\end{array}$ & $\begin{array}{l}0.756 \\
0.649\end{array}$ & $\begin{array}{l}0.710 \\
0.000\end{array}$ & $\begin{array}{l}0.000 \\
0.000\end{array}$ & $\begin{array}{l}0.321 \\
0.080\end{array}$ & 13.535 & $\begin{array}{l}1.26 \\
2\end{array}$ & $\begin{array}{l}0.294 \\
1.206\end{array}$ & $\begin{array}{l}0.585 \\
0.793\end{array}$ & $\begin{array}{l}0.000 \\
0.000\end{array}$ & $\begin{array}{l}0.000 \\
0.237\end{array}$ & $\begin{array}{l}0.124 \\
0.316\end{array}$ & 0.815 \\
\hline & & \multicolumn{7}{|c|}{ Version II } & \multicolumn{7}{|c|}{ Decentralized } \\
\hline Baseline & $\begin{array}{l}1 \\
2\end{array}$ & $\begin{array}{l}1.28 \\
2\end{array}$ & $\begin{array}{l}0.319 \\
1.181\end{array}$ & $\begin{array}{l}0.597 \\
0.801\end{array}$ & $\begin{array}{l}0.000 \\
0.000\end{array}$ & $\begin{array}{l}0.006 \\
0.156\end{array}$ & $\begin{array}{l}0.081 \\
0.206\end{array}$ & 0.711 & $\begin{array}{l}1.457 \\
2.000\end{array}$ & $\begin{array}{l}0.561 \\
0.939\end{array}$ & $\begin{array}{l}0.680 \\
0.749\end{array}$ & $\begin{array}{l}0.000 \\
0.000\end{array}$ & $\begin{array}{l}0.086 \\
0.147\end{array}$ & $\begin{array}{l}0.114 \\
0.185\end{array}$ & 0.000 \\
\hline$\theta=1.5$ & $\begin{array}{l}1 \\
2\end{array}$ & $\begin{array}{l}1.27 \\
2\end{array}$ & $\begin{array}{l}0.306 \\
1.194\end{array}$ & $\begin{array}{l}0.404 \\
0.683\end{array}$ & $\begin{array}{l}0.000 \\
0.000\end{array}$ & $\begin{array}{l}0.002 \\
0.159\end{array}$ & $\begin{array}{l}0.082 \\
0.211\end{array}$ & 0.369 & $\begin{array}{l}1.493 \\
2.000\end{array}$ & $\begin{array}{l}0.614 \\
0.886\end{array}$ & $\begin{array}{l}0.531 \\
0.591\end{array}$ & $\begin{array}{l}0.000 \\
0.000\end{array}$ & $\begin{array}{l}0.100 \\
0.147\end{array}$ & $\begin{array}{l}0.125 \\
0.184\end{array}$ & 0.000 \\
\hline$\theta=3.5$ & $\begin{array}{l}1 \\
2\end{array}$ & $\begin{array}{l}1.28 \\
2\end{array}$ & $\begin{array}{l}0.319 \\
1.181\end{array}$ & $\begin{array}{l}0.637 \\
0.824\end{array}$ & $\begin{array}{l}0.000 \\
0.000\end{array}$ & $\begin{array}{l}0.005 \\
0.155\end{array}$ & $\begin{array}{l}0.080 \\
0.205\end{array}$ & 0.580 & $\begin{array}{l}1.000 \\
2.000\end{array}$ & $\begin{array}{l}0.000 \\
1.500\end{array}$ & $\begin{array}{l}0.002 \\
0.884\end{array}$ & $\begin{array}{l}0.000 \\
0.000\end{array}$ & $\begin{array}{l}0.545 \\
0.159\end{array}$ & $\begin{array}{l}0.131 \\
0.238\end{array}$ & 0.000 \\
\hline$\alpha$ low & $\begin{array}{l}1 \\
2\end{array}$ & $\begin{array}{l}1.29 \\
2\end{array}$ & $\begin{array}{l}0.332 \\
1.168\end{array}$ & $\begin{array}{l}0.600 \\
0.798\end{array}$ & $\begin{array}{l}0.000 \\
0.000\end{array}$ & $\begin{array}{l}0.005 \\
0.125\end{array}$ & $\begin{array}{l}0.064 \\
0.164\end{array}$ & 0.507 & $\begin{array}{l}1.484 \\
2.000\end{array}$ & $\begin{array}{l}0.600 \\
0.900\end{array}$ & $\begin{array}{l}0.690 \\
0.740\end{array}$ & $\begin{array}{l}0.000 \\
0.000\end{array}$ & $\begin{array}{l}0.073 \\
0.116\end{array}$ & $\begin{array}{l}0.094 \\
0.144\end{array}$ & 0.000 \\
\hline$\alpha$ high & $\begin{array}{l}1 \\
2\end{array}$ & $\begin{array}{l}1.27 \\
2\end{array}$ & $\begin{array}{l}0.306 \\
1.194\end{array}$ & $\begin{array}{l}0.594 \\
0.804\end{array}$ & $\begin{array}{l}0.000 \\
0.000\end{array}$ & $\begin{array}{l}0.007 \\
0.187\end{array}$ & $\begin{array}{l}0.099 \\
0.248\end{array}$ & 0.867 & $\begin{array}{l}1.426 \\
2.000\end{array}$ & $\begin{array}{l}0.517 \\
0.983\end{array}$ & $\begin{array}{l}0.668 \\
0.760\end{array}$ & $\begin{array}{l}0.000 \\
0.000\end{array}$ & $\begin{array}{l}0.096 \\
0.179\end{array}$ & $\begin{array}{l}0.133 \\
0.228\end{array}$ & 0.000 \\
\hline$\gamma$ low & $\begin{array}{l}1 \\
2\end{array}$ & $\begin{array}{l}1.28 \\
2\end{array}$ & $\begin{array}{l}0.319 \\
1.181\end{array}$ & $\begin{array}{l}0.581 \\
0.780\end{array}$ & $\begin{array}{l}0.000 \\
0.000\end{array}$ & $\begin{array}{l}0.006 \\
0.156\end{array}$ & $\begin{array}{l}0.081 \\
0.206\end{array}$ & 0.719 & $\begin{array}{l}1.441 \\
2.000\end{array}$ & $\begin{array}{l}0.538 \\
0.962\end{array}$ & $\begin{array}{l}0.656 \\
0.733\end{array}$ & $\begin{array}{l}0.000 \\
0.000\end{array}$ & $\begin{array}{l}0.082 \\
0.149\end{array}$ & $\begin{array}{l}0.112 \\
0.188\end{array}$ & 0.000 \\
\hline$\gamma$ high & $\begin{array}{l}1 \\
2\end{array}$ & $\begin{array}{l}1.28 \\
2\end{array}$ & $\begin{array}{l}0.319 \\
1.181\end{array}$ & $\begin{array}{l}0.612 \\
0.821\end{array}$ & $\begin{array}{l}0.000 \\
0.000\end{array}$ & $\begin{array}{l}0.006 \\
0.155\end{array}$ & $\begin{array}{l}0.081 \\
0.205\end{array}$ & 0.689 & $\begin{array}{l}1.470 \\
2.000\end{array}$ & $\begin{array}{l}0.581 \\
0.919\end{array}$ & $\begin{array}{l}0.702 \\
0.764\end{array}$ & $\begin{array}{l}0.000 \\
0.000\end{array}$ & $\begin{array}{l}0.090 \\
0.146\end{array}$ & $\begin{array}{l}0.116 \\
0.183\end{array}$ & 0.000 \\
\hline$\beta_{x}$ low & $\begin{array}{l}1 \\
2\end{array}$ & $\begin{array}{l}1.27 \\
2\end{array}$ & $\begin{array}{l}0.306 \\
1.194\end{array}$ & $\begin{array}{l}0.595 \\
0.807\end{array}$ & $\begin{array}{l}0.000 \\
0.000\end{array}$ & $\begin{array}{l}0.001 \\
0.161\end{array}$ & $\begin{array}{l}0.083 \\
0.213\end{array}$ & 0.745 & $\begin{array}{l}1.448 \\
2.000\end{array}$ & $\begin{array}{l}0.549 \\
0.951\end{array}$ & $\begin{array}{l}0.680 \\
0.755\end{array}$ & $\begin{array}{l}0.000 \\
0.000\end{array}$ & $\begin{array}{l}0.089 \\
0.152\end{array}$ & $\begin{array}{l}0.117 \\
0.192\end{array}$ & 0.000 \\
\hline$\beta_{x}$ high & $\begin{array}{l}1 \\
2\end{array}$ & $\begin{array}{l}1.28 \\
2\end{array}$ & $\begin{array}{l}0.319 \\
1.181\end{array}$ & $\begin{array}{l}0.593 \\
0.798\end{array}$ & $\begin{array}{l}0.000 \\
0.000\end{array}$ & $\begin{array}{l}0.003 \\
0.151\end{array}$ & $\begin{array}{l}0.077 \\
0.199\end{array}$ & 0.717 & $\begin{array}{l}1.466 \\
2.000\end{array}$ & $\begin{array}{l}0.574 \\
0.926\end{array}$ & $\begin{array}{l}0.680 \\
0.743\end{array}$ & $\begin{array}{l}0.000 \\
0.000\end{array}$ & $\begin{array}{l}0.084 \\
0.143\end{array}$ & $\begin{array}{l}0.111 \\
0.178\end{array}$ & 0.000 \\
\hline$\beta_{h}$ low & $\begin{array}{l}1 \\
2\end{array}$ & $\begin{array}{l}1.28 \\
2\end{array}$ & $\begin{array}{l}0.319 \\
1.181\end{array}$ & $\begin{array}{l}0.581 \\
0.778\end{array}$ & $\begin{array}{l}0.000 \\
0.000\end{array}$ & $\begin{array}{l}0.007 \\
0.160\end{array}$ & $\begin{array}{l}0.083 \\
0.211\end{array}$ & 0.768 & $\begin{array}{l}1.441 \\
2.000\end{array}$ & $\begin{array}{l}0.538 \\
0.962\end{array}$ & $\begin{array}{l}0.653 \\
0.735\end{array}$ & $\begin{array}{l}0.000 \\
0.000\end{array}$ & $\begin{array}{l}0.085 \\
0.152\end{array}$ & $\begin{array}{l}0.115 \\
0.192\end{array}$ & 0.000 \\
\hline$\beta_{h}$ high & $\begin{array}{l}1 \\
2\end{array}$ & $\begin{array}{l}1.28 \\
2\end{array}$ & $\begin{array}{l}0.319 \\
1.181\end{array}$ & $\begin{array}{l}0.613 \\
0.823\end{array}$ & $\begin{array}{l}0.000 \\
0.000\end{array}$ & $\begin{array}{l}0.005 \\
0.151\end{array}$ & $\begin{array}{l}0.078 \\
0.200\end{array}$ & 0.628 & $\begin{array}{l}1.470 \\
2.000\end{array}$ & $\begin{array}{l}0.580 \\
0.920\end{array}$ & $\begin{array}{l}0.706 \\
0.764\end{array}$ & $\begin{array}{l}0.000 \\
0.000\end{array}$ & $\begin{array}{l}0.086 \\
0.143\end{array}$ & $\begin{array}{l}0.112 \\
0.179\end{array}$ & 0.000 \\
\hline WWs inc & $\begin{array}{l}1 \\
2\end{array}$ & $\begin{array}{l}1.86 \\
2\end{array}$ & $\begin{array}{l}1.230 \\
0.270\end{array}$ & $\begin{array}{l}0.827 \\
0.542\end{array}$ & $\begin{array}{l}0.000 \\
0.000\end{array}$ & $\begin{array}{l}0.149 \\
0.006\end{array}$ & $\begin{array}{l}0.193 \\
0.089\end{array}$ & -0.496 & $\begin{array}{l}1.457 \\
2.000\end{array}$ & $\begin{array}{l}0.561 \\
0.939\end{array}$ & $\begin{array}{l}0.680 \\
0.749\end{array}$ & $\begin{array}{l}0.000 \\
0.000\end{array}$ & $\begin{array}{l}0.086 \\
0.147\end{array}$ & $\begin{array}{l}0.114 \\
0.185\end{array}$ & 0.000 \\
\hline WWs dec & $\begin{array}{l}1 \\
2\end{array}$ & $\begin{array}{l}1.56 \\
2\end{array}$ & $\begin{array}{l}0.717 \\
0.783\end{array}$ & $\begin{array}{l}0.725 \\
0.710\end{array}$ & $\begin{array}{l}0.000 \\
0.000\end{array}$ & $\begin{array}{l}0.110 \\
0.137\end{array}$ & $\begin{array}{l}0.134 \\
0.168\end{array}$ & -0.375 & $\begin{array}{l}1.457 \\
2.000\end{array}$ & $\begin{array}{l}0.561 \\
0.939\end{array}$ & $\begin{array}{l}0.680 \\
0.749\end{array}$ & $\begin{array}{l}0.000 \\
0.000\end{array}$ & $\begin{array}{l}0.086 \\
0.147\end{array}$ & $\begin{array}{l}0.114 \\
0.185\end{array}$ & 0.000 \\
\hline
\end{tabular}

Note. "high" and "low" refer to $20 \%$ above and $20 \%$ below the respective baseline value. "WWs" are welfare weights of households in the social welfare function (in the baseline version, each welfare weight is 1); for "WWs inc", welfare weights increase $(1,2 \ldots, 101)$ and for "WWs dec" they decrease $(101,100, \ldots, 1)$. 


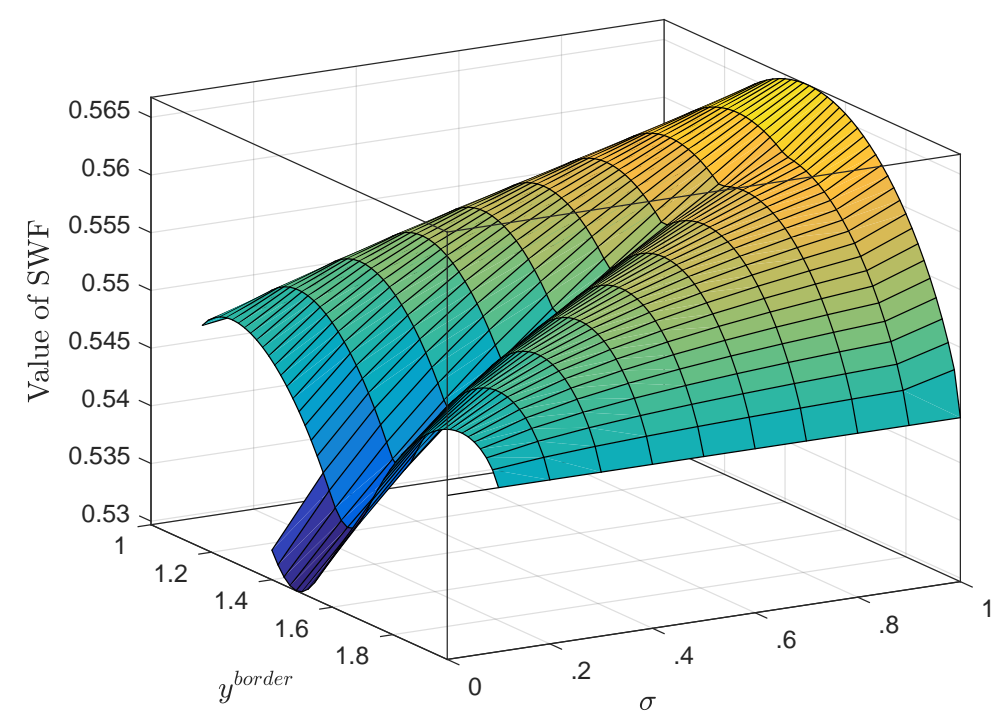

Figure A1: First-best value of the social welfare function (SWF) for variations in the level of spillovers $\sigma$ and the border household $y^{\text {border }}$.

This surface plot describes the value of the SWF with $\rho=0.5$. The degree of spillovers increases from left to right. From the front to the back, the border household $\left(y^{\text {border }}\right)$ between both municipalities varies. There are three saddle-points of the SWF: a minimum at $y^{\text {border }}=1.5$, a local maximum that would imply a small rich municipality, and a global maximum with a small, poor municipality. The path along this saddle point is reported in Table A4 (for $\rho=0.5$ ). Note that with perfect spillovers (at the right), dividing the population equally between both municipalities turns out to be optimal.

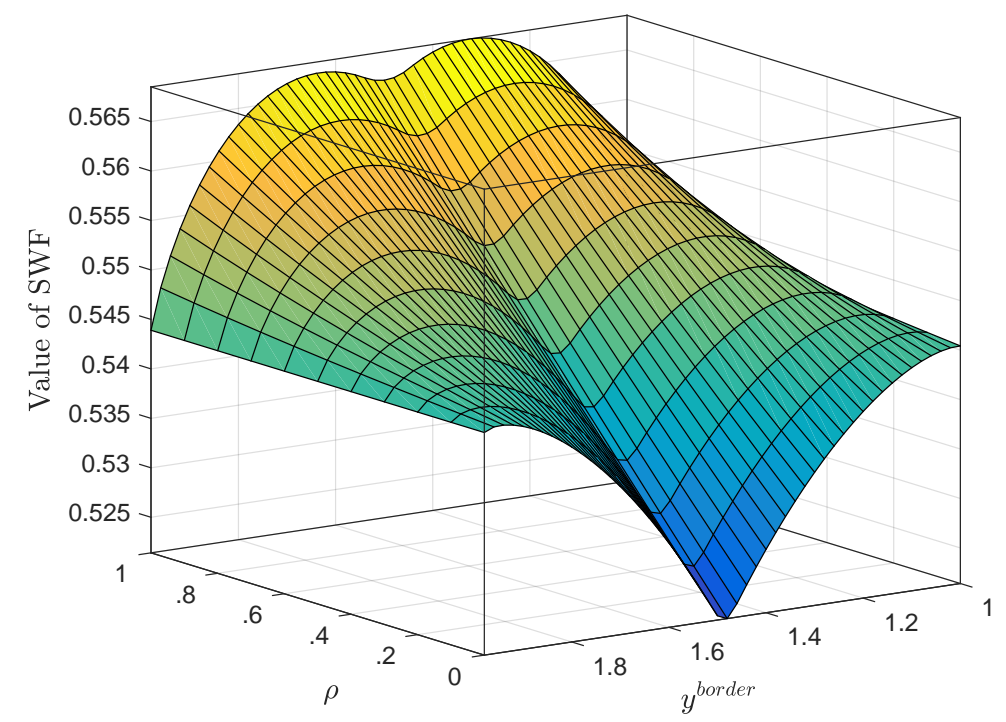

Figure A2: First-best value of the social welfare function (SWF) for variations in the level of rivalry $\rho$ and the border household $y^{\text {border }}$.

This surface plot describes the achievable value of the SWF with $\sigma=0.3$. The degree of rivalry decreases from the back to the front. From left to right, the border household $\left(y^{\text {border }}\right)$ varies. There are three saddle-points of the SWF: a minimum at $y^{\text {border }}=1.5$, a local maximum that would imply a small rich municipality, and the global maximum with a small, poor municipality. The path along the latter is reported in Table A4 (for $\sigma=0.3)$. 


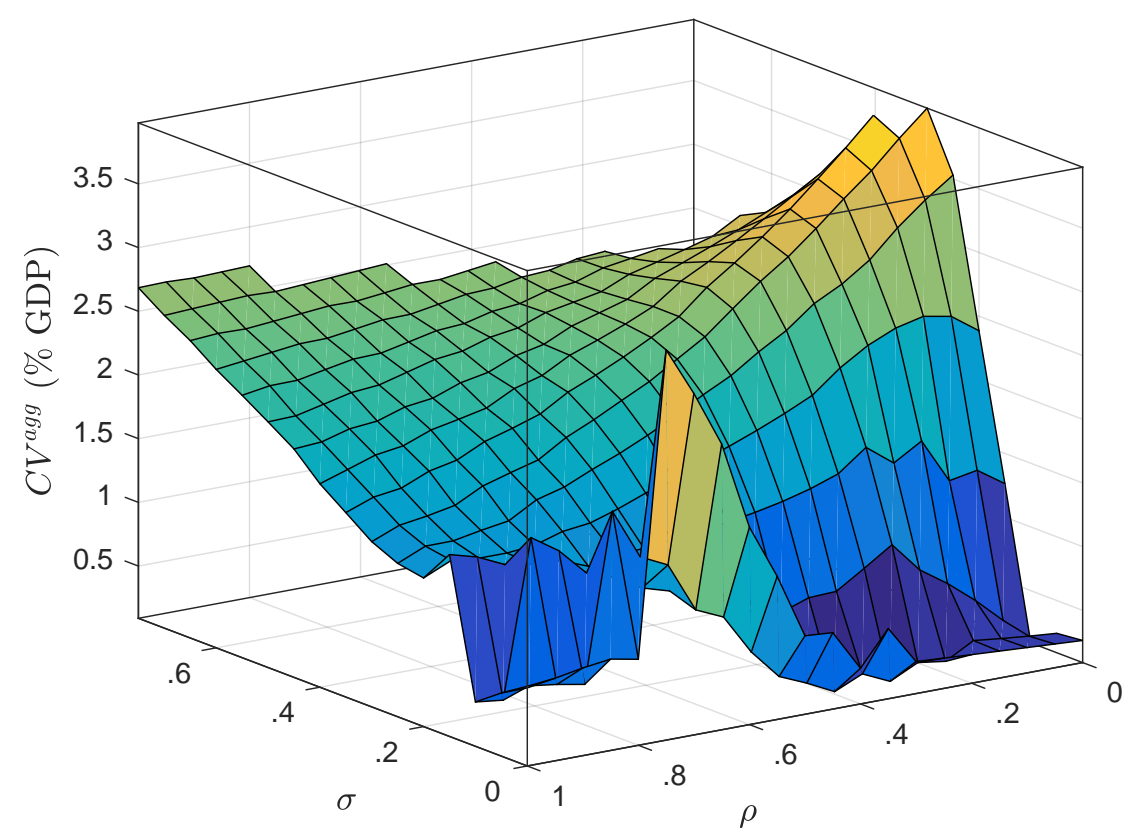

Figure A3: First-best vs. decentralized equilibrium: Aggregated compensating variation $\left(C V^{a g g}\right)$ in $\%$ of total income for $\sigma$ and $\rho$ variations.

For $\sigma>0.78$ and combinations of $\rho$ sufficiently small and $\sigma$ sufficiently large, we could not establish decentralized income-segregating equilibria, as discussed in Section 3.3. Therefore, we could not compute aggregate compensating variation levels for all combinations of $\sigma$ and $\rho$, indicated by the 'border' of the surface in the upper left of the figure. Note finally, that results depicted for $\sigma=0$ are those for $\sigma=0.01$, since we had computational problems for some combinations with $\sigma=0$.
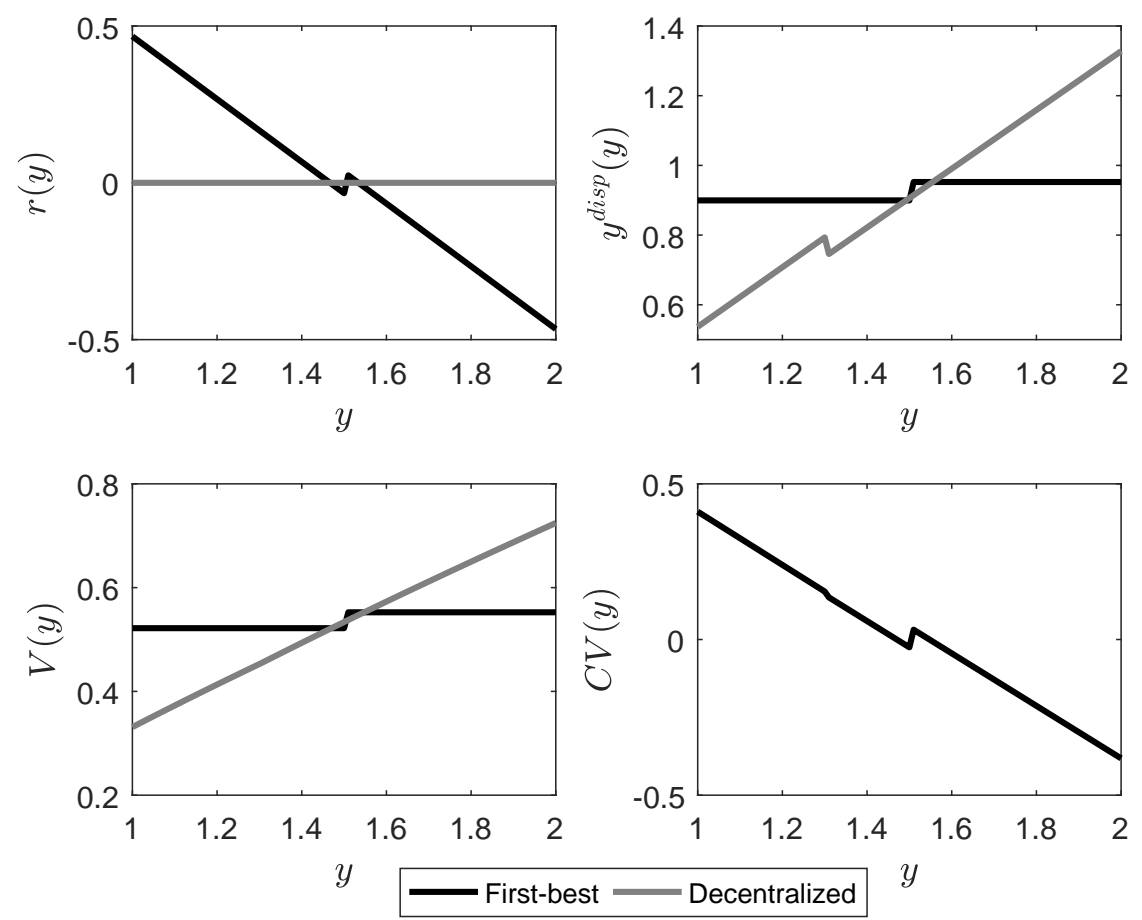

Figure A4: Household characteristics in FB and the fully decentralized equilibrium for a publicly provided private good $(\sigma=0, \rho=1)$ : Individual transfer scheme $r(y)$, disposable income $y^{\text {disp }}(y)$, utility level $V(y)$, and compensating variation $C V(y)$.

The small kinks in the first-best (black) lines above are the result of relying on a finite number of households (101 in our case) to solve our model numerically. However, we do not split up the mass of households at the border household, but assign them to one of the two municipalities, which implies that both municipalities are not exactly equally inhabited. Increasing the number of modeled household types would smooth out these kinks. 